\title{
Magnetic local time, substorm, and particle precipitation-related variations in the behaviour of SuperDARN Doppler spectral widths
}

\author{
M. L. Parkinson ${ }^{1}$, G. Chisham ${ }^{2}$, M. Pinnock ${ }^{2}$, P. L. Dyson ${ }^{1}$, and J. C. Devlin ${ }^{3}$ \\ ${ }^{1}$ Department of Physics, La Trobe University, Victoria 3086, Australia \\ ${ }^{2}$ British Antarctic Survey, Natural Environment Research Council, Cambridge CB3 0ET, UK \\ ${ }^{3}$ Department of Electronic Engineering, La Trobe University, Victoria 3086, Australia
}

Received: 20 August 2003 - Revised: 23 June 2004 - Accepted: 5 October 2004 - Published: 22 December 2004

\begin{abstract}
Super Dual Auroral Radar Network (DARN) radars often detect a distinct transition in line-of-sight Doppler velocity spread, or spectral width, from $<50 \mathrm{~m} \mathrm{~s}^{-1}$ at lower latitude to $>200 \mathrm{~m} \mathrm{~s}^{-1}$ at higher latitude. They also detect a similar boundary, namely the range at which ionospheric scatter with large spectral width suddenly commences (i.e. without preceding scatter with low spectral width). The location and behaviour of the spectral width boundary (SWB) (and scatter boundary) and the open-closed magnetic field line boundary (OCB) are thought to be closely related. The location of the nightside OCB can be inferred from the poleward edge of the auroral oval determined using energy spectra of precipitating particles measured on board Defence Meteorology Satellite Program (DMSP) satellites. Observations made with the Halley SuperDARN $\operatorname{radar}\left(75.5^{\circ} \mathrm{S}, 26.6^{\circ} \mathrm{W}\right.$, geographic; $\left.-62.0^{\circ} \Lambda\right)$ and the Tasman International Geospace Environment Radar (TIGER) $\left(43.4^{\circ} \mathrm{S}, 147.2^{\circ} \mathrm{E} ;-54.5^{\circ} \Lambda\right)$ are used to compare the location of the SWB with the DMSP-inferred OCB during 08:00 to 22:00 UT on 1 April 2000. This study interval was chosen because it includes several moderate substorms, whilst the Halley radar provided almost continuous high-time resolution measurements of the dayside SWB location and shape, and TIGER provided the same in the nightside ionosphere. The behaviour of the day- and nightside SWB can be understood in terms of the expanding/contracting polar cap model of high-latitude convection change, and the behaviour of the nightside SWB can also be organised according to substorm phase. Previous comparisons with DMSP OCBs have proven that the radar SWB is often a reasonable proxy for the OCB from dusk to just past midnight (Chisham et al., 2004). However, the present case study actually suggests that the nightside SWB is often a better proxy for the poleward edge of Pedersen conductance enhanced by hot particle precipitation in the auroral zone. Simple modeling implies that the large spectral widths must be caused by $\sim 10-\mathrm{km}$ scale velocity fluctuations.
\end{abstract}

Correspondence to: M. L. Parkinson

(m.parkinson@latrobe.edu.au)
Key words. Ionosphere (auroral ionosphere; ionospheremagnetosphere interactions) - Magnetospheric physics (storms and substorms)

\section{Introduction}

Changes in the latitude and shape of the open-closed magnetic field line boundary (OCB) are a direct indication of energy coupling in the solar wind-magnetosphere-ionosphere system. The dynamics of the OCB can be understood in the context of the expanding/contracting polar cap model of high-latitude convection change (Siscoe and Huang, 1985; Cowley and Lockwood, 1992). This mechanistic model explains how the area of the polar cap ionosphere, or the geomagnetic region open to the IMF, inflates when dayside reconnection proceeds at a faster rate than nightside reconnection, and conversely, deflates when reconnection in the tail dominates. The behaviour of the OCB can also be understood in the context of the global substorm instability, namely the cyclic but poorly understood loading and unloading of energy in the magnetotail (Baker et al., 1999; Lui, 2001).

Thus, it is very important to determine if, and when, various features observed by different ground-based instruments, for example, the Doppler spectral width boundary (SWB) observed by Super Dual Auroral Radar Network (SuperDARN) radars, correspond to the OCB under a broad range of geophysical conditions, including ionospheric substorms. Other proxies for the OCB include the poleward edge of $630.0-\mathrm{nm}$ auroral emission (Blanchard et al., 1997), and the poleward edge of the auroral oval measured in situ by spacecraft (Vampola, 1971; Evans and Stone, 1972). For example, the OCB can be inferred from spectrograms of precipitating particles measured on board the Defense Meteorological Satellite Program (DMSP) spacecraft.

The SuperDARN network of HF backscatter radars was established to monitor high-latitude ionospheric convection on a global scale (Greenwald et al., 1985, 1995). SuperDARN presently consists of 9 radars encircling the northern polar cap, and 7 radars encircling the southern polar cap. 
Each radar employs a 16-element, 240-m wide phased antenna array to produce an $\sim 4^{\circ}$-wide main beam (at $12 \mathrm{MHz}$ ). During routine operation, this beam is sequentially stepped through 16 directions separated in azimuth by $3.24^{\circ}$, thereby forming a $\sim 52^{\circ}$-wide field of view (FOV).

Bragg-type backscatter is obtained from ionospheric irregularities with a field-perpendicular scale size equal to half the radio-wavelength, equal to $12.5 \mathrm{~m}$ at $12 \mathrm{MHz}$. Basic echo parameters, including the backscatter power, line-ofsight (LOS) Doppler velocity, and Doppler velocity spread (or "spectral width"), are calculated using "FITACF," an algorithm which fits Gaussian and Lorentzian functions to the autocorrelation functions (Baker et al., 1995). During routine operation, FITACF parameters are usually recorded once every $1-2 \mathrm{~min}$ at any of 70 ranges between 180 to $3330 \mathrm{~km}$ in 45-km steps.

The backscatter power is a measure of the number and relative intensity of electron density irregularities within the ionospheric sampling volume (Parkinson et al., 2003a), as well as the effects of ionospheric absorption, and focusing and defocusing of the radio beams. The LOS Doppler velocities are a measure of field-perpendicular electric fields when the backscatter emanates from the F-region of the ionosphere (Villain et al., 1985) and the upper E-region (Parkinson et al., 1997). Lastly, the spectral widths are a measure of the lifetime of ionospheric irregularities, as well as space and time variations in the LOS Doppler velocity occurring within the sampling volume and integration time.

Non-uniform convection flows from small $(\sim 1 \mathrm{~km})$ to large scales $(\sim 1000 \mathrm{~km})$ (Parkinson et al., 1999), micro-scale $(\sim 10 \mathrm{~m})$ plasma turbulence, and electric field variations in the Pc 1-2 frequency range, may all play a possible role in increasing the radar spectral widths. However, the large spectral widths encountered in the auroral and cusp ionosphere cannot be explained by large-scale variations in the convection pattern (André et al., 2000b). André et al. (1999, 2000a) modeled the SuperDARN measurement process and argued that the large spectral widths are caused by electric field variations in the Pc 1-2 frequency range. However, Ponomarenko and Waters (2003) found an error in the calculus of André et al. The small-scale process causing large spectral widths observed in the cusp and nightside ionosphere is still an open question.

A distinct transition in spectral width from $<50 \mathrm{~m} \mathrm{~s}^{-1}$ at lower latitude to $>200 \mathrm{~m} \mathrm{~s}^{-1}$ at higher latitude is often observed in the dayside ionosphere. This spectral width boundary (SWB) has been interpreted as a proxy for the openclosed magnetic field line boundary (OCB) when the interplanetary magnetic field (IMF) $B_{z}$ component is southward (Baker et al., 1995; Milan et al., 1998; Moen et al., 2001). The dayside scatter with large spectral widths expands equatorward and contracts poleward when the IMF $B_{z}$ component increases and decreases, respectively (Pinnock et al., 1993).

Chisham et al. (2001) observed an equatorward expansion of a dayside bulge in the SWB, perhaps signifying the accumulation of open flux during dayside reconnection when the IMF $B_{y}$ component changed in sign. On the other hand, the SWB sometimes exhibits a poleward directed, bay-like feature in proximity to the cusp (Pinnock and Rodger, 2001). Chisham et al. (2002) argued that these bays indicate that the SWB is sometimes displaced poleward of the true OCB because of "the poleward motion of newly-reconnected magnetic field lines during the cusp ion travel time from the reconnection X-line to the ionosphere". Associating the radar SWB with an ionospheric precipitation boundary implies it may not always be exactly coincident with the instantaneous location of the OCB.

SuperDARN radars often observe a similar SWB in other magnetic local time (MLT) sectors, including the midnight auroral ionosphere. Recently, the interpretation of the nightside SWB has varied. Early work suggested it corresponds to the boundary between the central plasma sheet (CPS) and the so-called boundary plasma sheet (BPS) (Lewis et al., 1997, 1998; Dudeney at al., 1998). More recent studies suggest that the nightside SWB may actually correspond to the OCB under favourable conditions (Lester et al., 2001; Parkinson et al., 2002b, 2003b ${ }^{1}$ ). However, after comparing EISCAT and CUTLASS radar data, Woodfield et al. (2002a, b) questioned whether the SWB was a reliable proxy for the OCB in the post-midnight sector.

Thus, the purpose of this paper is threefold, namely to further investigate (i) problems associated with identifying the SWB, including the all-important effects of HF propagation, (ii) whether the nightside SWB is a reliable proxy for the OCB in different MLT sectors and for various geomagnetic activity levels, including ionospheric substorms, and (iii) the behaviour of the nightside SWB with respect to the behaviour of the dayside SWB in the context of the expanding/contracting polar cap model of high-latitude convection change. Thereby we gain further insights into the cause and true identity of the SWB.

To these ends, we analyse dual SuperDARN radar measurements made on 1 April 2000 containing $\sim 12 \mathrm{~h}$ of continuous day- and nightside ionospheric scatter with persistent SWBs. We compare and contrast the SWBs with the poleward edge of the auroral oval identified from spectrograms of precipitating particles measured on board the DMSP spacecraft. The dayside SWB responded rapidly to changing IMF and solar wind conditions, and in ways closely related to that expected for the dayside $\mathrm{OCB}$, and the behaviour of the nightside SWB was organized according to substorm phase. However, the comparison with energetic precipitating particles measured on board DMSP, combined with a synthesis of observations reported elsewhere, actually suggests that the nightside SWB is often a better proxy for the poleward edge of height-integrated Pedersen conductivity enhanced by hot particle precipitation in the auroral zone.

\footnotetext{
${ }^{1}$ Parkinson, M. L., Pinnock, M., Dyson, P. L., and Devlin, J. C.: Signatures of the nightside open-closed magnetic field-line boundary during moderately disturbed conditions and ionospheric substorms, Adv. Space Res., submitted, 2003b.
} 


\section{Experiment}

Observations reported here were made with the Halley SuperDARN radar $\left(75.5^{\circ} \mathrm{S}, 26.6^{\circ} \mathrm{W}\right.$, geographic; $\left.-62.0^{\circ} \Lambda\right)$ and the Tasman International Geospace Environment Radar (TIGER) $\left(43.4^{\circ} \mathrm{S}, 147.2^{\circ} \mathrm{E} ;-54.5^{\circ} \Lambda\right.$ ) (Dyson and Devlin, 2000). Magnetic latitudes given here were calculated using altitude adjusted corrected geomagnetic co-ordinates (AACGM) (Baker and Wing, 1989). Because of Halley's more poleward location, it is more favourably located for observation of the dayside cusp than TIGER; conversely, the TIGER radar is more favourably located to observe the auroral ionosphere in the midnight sector. Note that the spectral widths located in the pre-noon cusp are typically larger than those located in the nightside ionosphere (Villain et al., 2002; Parkinson et al., 2003a).

Figure 1 shows two scans each of the Halley (red) and TIGER (blue) radars mapped to co-ordinates consisting of MLT and AACGM latitude. The mapping to true ground range assumes a virtual reflection height of $300 \mathrm{~km}$. These scans were made at different UTs, chosen to illustrate various features in the spectral widths to be discussed later. In reality, the FOVs of the two radars are located nearly diametrically opposite the AACGM pole.

In Fig. 1, for example, the Halley scan at 17:03:40 UT shows very large spectral widths $\left(>300 \mathrm{~m} \mathrm{~s}^{-1}\right)$ which must be located just poleward of the region mapping to reconnection under these strong $B_{z}$ southward conditions (Baker et al., 1995; Milan et al., 1998; Moen et al., 2001). However, very low spectral widths $\left(<100 \mathrm{~m} \mathrm{~s}^{-1}\right)$ were present in the central polar cap ionosphere, and this provides an important clue about the mechanism regulating the spectral widths. The TIGER scan at 10:04:04 UT shows a dramatic equatorward tilt of the SWB/scatter boundary in the pre-midnight sector, and the scan at 14:09:35 UT shows extensive regions of low spectral width $\left(<100 \mathrm{~m} \mathrm{~s}^{-1}\right)$ equatorward of the SWB.

The chosen study interval, 08:00 to 22:00 UT on 1 April 2000 (see Fig. 3), is noteworthy because of the persistent ionospheric scatter with clear SWBs recorded concurrently by both radars. Both radars also ran high-time resolution "camping" beams. Halley beam 8 and TIGER beam 4 soundings were interleaved between routine 16-beam scans. The chosen integration time was $3 \mathrm{~s}$, so the total scan time was $16 \times 2 \times 3 \mathrm{~s}=96 \mathrm{~s}$ (but slightly longer when allowing for housekeeping by the radar operating system). Halley beam 8 and TIGER beam 4 are magnetic meridian pointing beams, and are the most useful beams for accurately defining the SWB when it is magnetic $L$-shell aligned.

Chisham and Freeman $(2003,2004)$ (C-F hereafter) explain an improved method of identifying the radar SWB. They emphasise the importance of applying spatial and temporal median filters to prevent spurious fluctuations in spectral width causing miss-identification of the SWB. They also emphasise the importance of choosing a spectral width threshold about half-way between the median values of the spectral width distributions occurring above and below the SWB. We used a slightly modified version of the C-F algo-

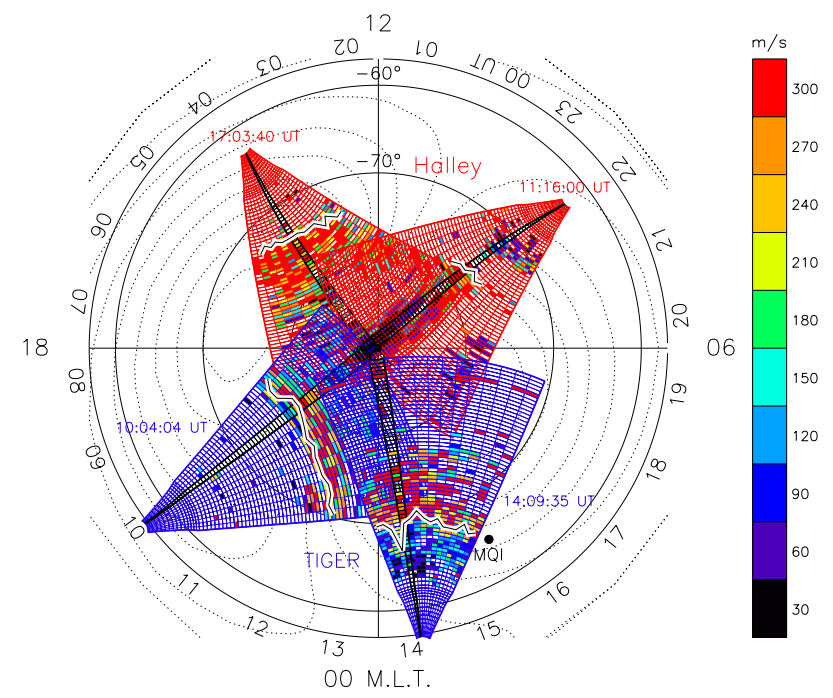

Fig. 1. Spectral widths recorded during two scans each of the Halley and TIGER radars mapped to co-ordinates consisting of MLT and AACGM latitude. Magnetic noon (12 h) is at top, magnetic dawn (6h) to the right, and UT at TIGER is also indicated. Halley beam 8 and TIGER beam 4 are shown in bold black. The Halley full scans commenced at 11:16:00 and 17:03:40 UT, and the TIGER full scans commenced at 10:04:04 and 14:09:35 UT. Equipotentials given by the DMSP satellite-based Ionospheric Convection Model (DICM) (Papitashvili and Rich, 2002) for $\left(B_{\mathrm{x}}, B_{\mathrm{y}}, B_{\mathrm{Z}}\right)=(7,-4,2) \mathrm{nT}$ are also superimposed (dotted). The minimum electric potential in the dusk cell is $-27.8 \mathrm{kV}$, the maximum potential in the dawn cell is $5.5 \mathrm{kV}$, and contours are separated by $2.5 \mathrm{kV}$.

rithm 3 to analyse our measurements. It was impractical to apply an initial spatial filter across adjacent beams because of the high-time resolution camping beams. This was partly compensated for by applying a median filter to 5 consecutive beams in the time domain at every range. This reduced the time resolution to $\sim 30 \mathrm{~s}$. The integrity of individual samples would need checking to infer behaviour of the spectral width boundary on shorter time scales.

The C-F results suggested that a spectral width threshold of $\sim 150 \mathrm{~m} \mathrm{~s}^{-1}$ or more is better suited for identifying the SWB using dayside cusp data recorded by Halley. A statistical analysis of Halley nightside data (Chisham et al., 2004) suggested that a threshold of $250 \mathrm{~m} \mathrm{~s}^{-1}$ achieved better agreement with the poleward edge of the nightside auroral oval, and thus the OCB. However, Fig. 9 of Parkinson et al. (2003a) suggested that a threshold as low as $\sim 38 \mathrm{~m} \mathrm{~s}^{-1}$ may be better suited for identifying the SWB in nightside data recorded by TIGER. The actual choice of threshold is not critical when the SWB is sharp and delineates a transition between well-separated spectral width distributions. Here we used a nominal threshold of $150 \mathrm{~m} \mathrm{~s}^{-1}$ for both Halley and TIGER radar data, but the actual value chosen does not effect the overall interpretation of our results.

Because of TIGER's more equatorward location, the miss-identification of slow, subauroral ionospheric scatter as ground scatter is a significant concern. In the case of TIGER, 


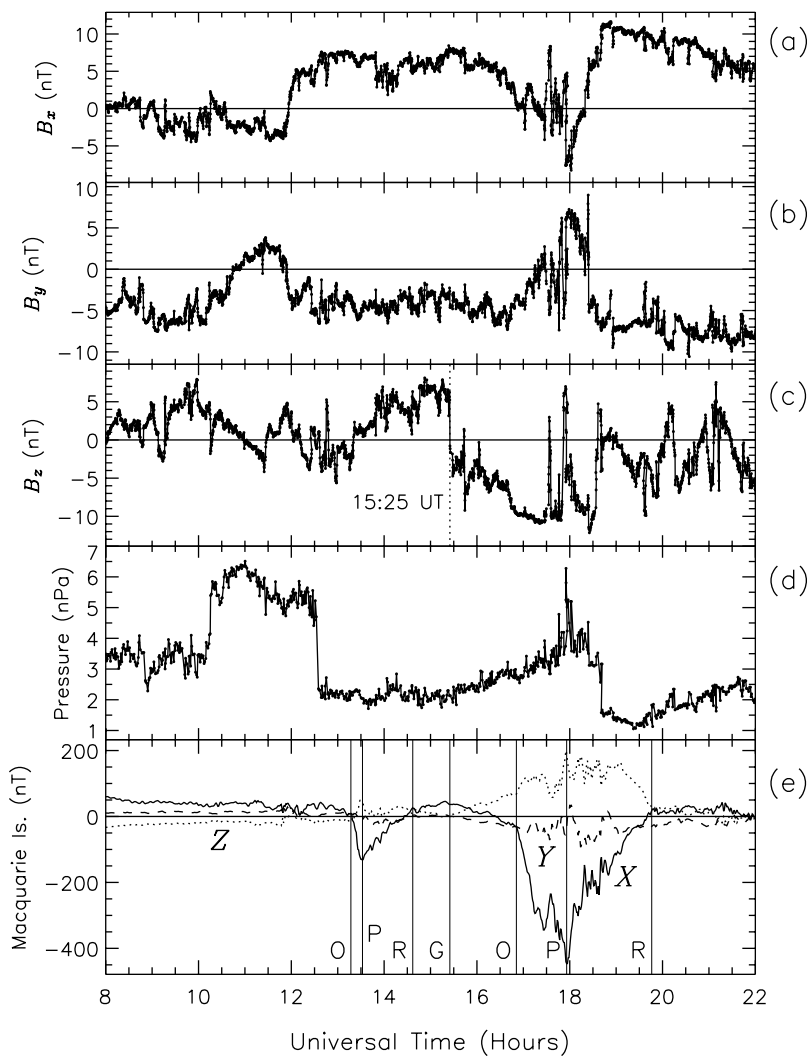

Fig. 2. ACE spacecraft measurements of the IMF (a) $B_{\mathrm{x}}$, (b) $B_{\mathrm{y}}$, and (c) $B_{\mathrm{Z}}$ components, and (d) the solar wind dynamic pressure, during 08:00 to 22:00 UT on 1 April 2000. The IMF samples are shown at 16-s resolution and the dynamic pressures at 64-s resolution. (e) Perturbations of the geomagnetic X (solid curve), Y (dashed curve), and $\mathrm{Z}$ (dotted curve) components measured by the Macquarie Is. (MQI) magnetometer (provided courtesy of Geoscience Australia).

the majority of ground scatter actually emanates from the sea. Note that including sea scatter in the C-F algorithm shifts the SWB slightly equatorward. However, we could not prove when sea scatter was actually ionospheric scatter, so it was not included when estimating the SWB location. The SWB identified using the $\mathrm{C}-\mathrm{F}$ algorithm has been superimposed on all full-scan data shown in Fig. 1 (black on white curves).

Changes in the energy spectra and pitch-angle distributions of precipitating particles at the poleward edge of the auroral oval indicate the location of the OCB (Vampola, 1971; Evans and Stone, 1972). Here we compare the location of radar SWBs with the results of analyzing energy spectra of precipitating particles measured on board the DMSP satellites, inserted in near polar orbits at an altitude of $\sim 830 \mathrm{~km}$ and a period of $101 \mathrm{~min}$ (e.g. Anderson et al., 1997). The nightside auroral oval boundaries shown here were those obtained by applying the logical criteria of Newell et al. (1996) to the energy spectra. Using the Newell et al. nomenclature, the most equatorward of the electron (b1e) or ion boundaries (b1i) was taken as the equatorward boundary of the auro- ral oval, and the most poleward of the electron (b5e) or ion boundaries (b5i) was taken as the poleward boundary (i.e. a low-altitude proxy for the OCB).

Auroral oval boundaries were obtained using four DMSP satellites, F12, F13, F14, and F15, during our study interval. Because these satellites are in Sun-synchronous orbits, they favour observations made at certain local times, and relatively few passes were directly through the TIGER FOV. To increase the number of boundaries suitable for comparison with the radar measurements, we considered all boundaries identified within $2 \mathrm{~h}$ MLT of the beam 4 longitude (i.e. $147.2^{\circ} \pm 30^{\circ} \mathrm{E}$ ). In practise, only 2 out of the $10 \mathrm{DMSP}$ boundaries used here were identified outside the radar FOV, and each DMSP boundary was compared with the radar SWB identified on the nearest spatially coincident beam.

Five errors were involved in comparing the DMSP and radar boundaries: (1) the error in estimating the OCB from the DMSP energy spectra because of ambiguities in determining the separation between auroral oval and polar cap precipitation, probably $<1^{\circ}$, (2) the small error in mapping the DMSP measurements to magnetic latitude, probably $<0.5^{\circ}$, (3) the error in mapping the radar scatter from group range to magnetic latitude, probably $<1^{\circ}$, (4) the error in defining the location of the radar SWB, probably $<1^{\circ}$, and (5) the error due to real fluctuations in either boundary that were too rapid in space and time to resolve, again probably $<1^{\circ}$. Hence adding these errors in quadrature, $\sqrt{ } 4.25^{\circ} \approx 2^{\circ}$, we obtain a plausible estimate of the maximum possible error when comparing the OCBs with the SWBs.

\section{Results}

\subsection{Solar wind and geomagnetic conditions}

Figure 2 summarises the solar wind and geomagnetic conditions during the chosen study interval, 08:00 to 22:00 UT, 1 April 2000. Parts (a) to (c) show the IMF $B_{\mathrm{x}}, B_{\mathrm{y}}$, and $B_{\mathrm{z}}$ components in geocentric solar magnetospheric (GSM) coordinates, respectively, and part (d) shows the solar wind dynamic pressure. The IMF values were measured at 16-s resolution on board the Advanced Composition Explorer (ACE) spacecraft, located at GSM x, y, and z co-ordinates of 227.9, -34.6 , and $-3.4 \mathrm{Re}$, respectively. The solar wind parameters were advected to ionospheric arrival times using GSM $x$ distances, whilst considering simultaneous IMP 8 and HF radar measurements, as explained by Parkinson et al. (2002c). The average time delay between ACE and the noon sector ionosphere was $\sim 58.5 \mathrm{~min}$.

The IMF $B_{\mathrm{y}}$ component was mostly in the range -3 to $-6 \mathrm{nT}$ during the study interval, except during $\sim 10: 45$ to 11:55 UT and $\sim 17: 15$ to 18:25 UT. The variation of $B_{\mathrm{Z}}$ was more complicated, but was mostly positive during $\sim 07: 55$ to 11:00 UT. It then underwent a succession of brief southward turnings to $B_{\mathrm{z}} \sim-4 \mathrm{nT}$ during $\sim 11: 00$ to $13: 21 \mathrm{UT}$. It then became strongly positive until 15:25 UT when a major, sharp, southward turning took place. The initial step-like 


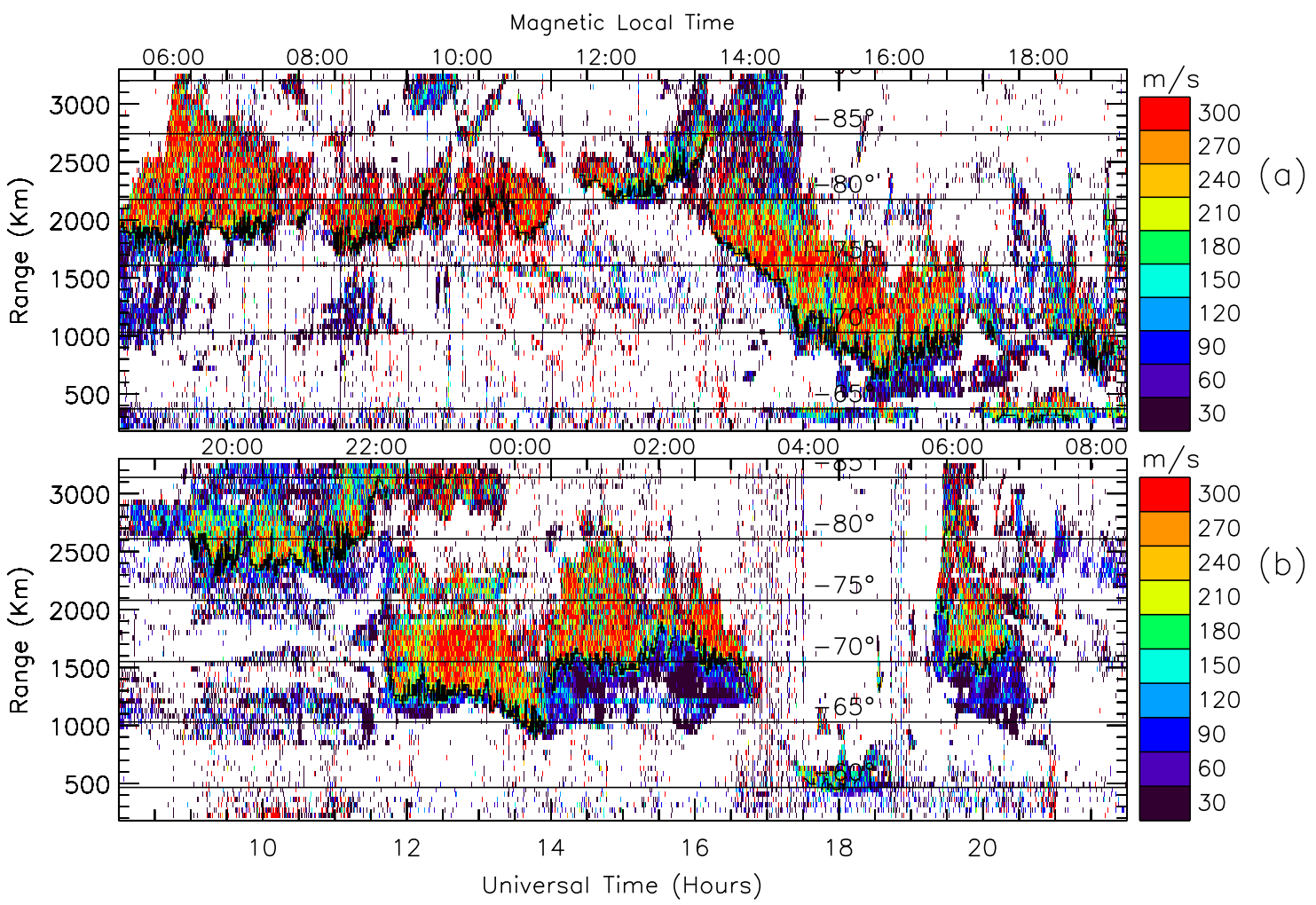

Fig. 3. Range-time plots of radar spectral widths measured on (a) Halley beam 8 and (b) TIGER beam 4 at 6-s time steps during 08:00 to 22:00 UT, 1 April 2000. Ground scatter generally has very low spectral widths and was not included in these plots. Significant changes in the operating frequency of TIGER occurred at 09:00 and 21:00 UT. Bold, fluctuating curves delineate the spectral width boundaries (SWBs) identified using the C-F algorithm with a threshold of $150 \mathrm{~m} \mathrm{~s}^{-1}$. The thin horizontal lines represent magnetic latitudes between $-65^{\circ}$ and $-85^{\circ}$, and corresponding MLTs are shown at the top of each panel.

decrease was to nearly $-5 \mathrm{nT}$, but was followed by a more gradual decline to $-11 \mathrm{nT}$ until 17:25 UT, when $B_{\mathrm{Z}}$ again began to trend back northward.

Four major features can be identified in the solar wind dynamic pressure: (1) a step-like increase from $\sim 3$ to $6 \mathrm{nPa}$ at $\sim 10: 15 \mathrm{UT},(2)$ a step-like decrease from $\sim 5$ to $2 \mathrm{nPa} 12: 35 \mathrm{UT}$, (3) a gradual rise to a peak of $6.3 \mathrm{nPa}$ at 17:56 UT, and (4) a step-like decrease from $3.5 \mathrm{nPa}$ to $1.5 \mathrm{nPa}$ at 18:40 UT. Although these pressure pulses are substantial, they produced relatively short-lived transients in the radar data (Thorolfson et al., 2001). A detailed analysis of their effects is beyond the scope of this study.

Figure 1 shows the location of Macquarie Island (MQI) $\left(54.5^{\circ} \mathrm{S}, 158.9^{\circ} \mathrm{E} ;-65^{\circ} \Lambda\right)$ at the time of the TIGER full scan, 14:09:35 UT. MQI always maintains the same position relative to the fixed TIGER FOV. MQI fluxgate magnetometer measurements provide the most relevant measure of local auroral electrojet activity. Figure 2e shows MQI magnetometer perturbations in the geomagnetic X (north), $\mathrm{Y}$ (east), and $\mathrm{Z}$ (down) components. These were calculated by transforming the absolute values to AACGM co-ordinates, and then de-trended by subtracting the daily means.

Two substorms occurred during the evening of 1 April 2000. The onset $(\mathrm{O})$ of a first small substorm occurred at 13:17 UT, the peak expansion phase $(\mathrm{P})$ at 13:32 UT $(\sim-122 \mathrm{nT})$, and the recovery phase ended $(\mathrm{R})$ near $\sim 14: 37$ UT. The growth phase (G) of a second, moderate substorm commenced near 15:25 UT, the onset near 16:51 UT, the peak expansion phase at 17:56 UT $(\sim-413 \mathrm{nT})$, and the recovery phase ended near $\sim 19: 46 \mathrm{UT}$. The ratio of $\mathrm{Z}$ to $\mathrm{X}$ perturbations indicate the westward current flow maximised almost directly above MQI for the first substorm, but just poleward of MQI for the second substorm. Whilst the accuracy of the substorm timings was not critical to the interpretation of our results, they were checked against CANOPUS magnetometer array and Los Alamos National Laboratory (LANL) satellite measurements of energetic particle injections.

\subsection{Dual radar measurements and spectral width bound-} aries

Figure 3 shows group range versus UT plots of the radar spectral widths measured at 6-s time steps using the hightime resolution camping beam 8 for Halley (a) and beam 4 for TIGER (b). The Halley observations span the dayside interval, $\sim 6$ to 18 MLT, whereas the TIGER observations span the nightside interval, $\sim 19$ to 08 MLT. The SWBs automatically identified using the C-F algorithm are superimposed 


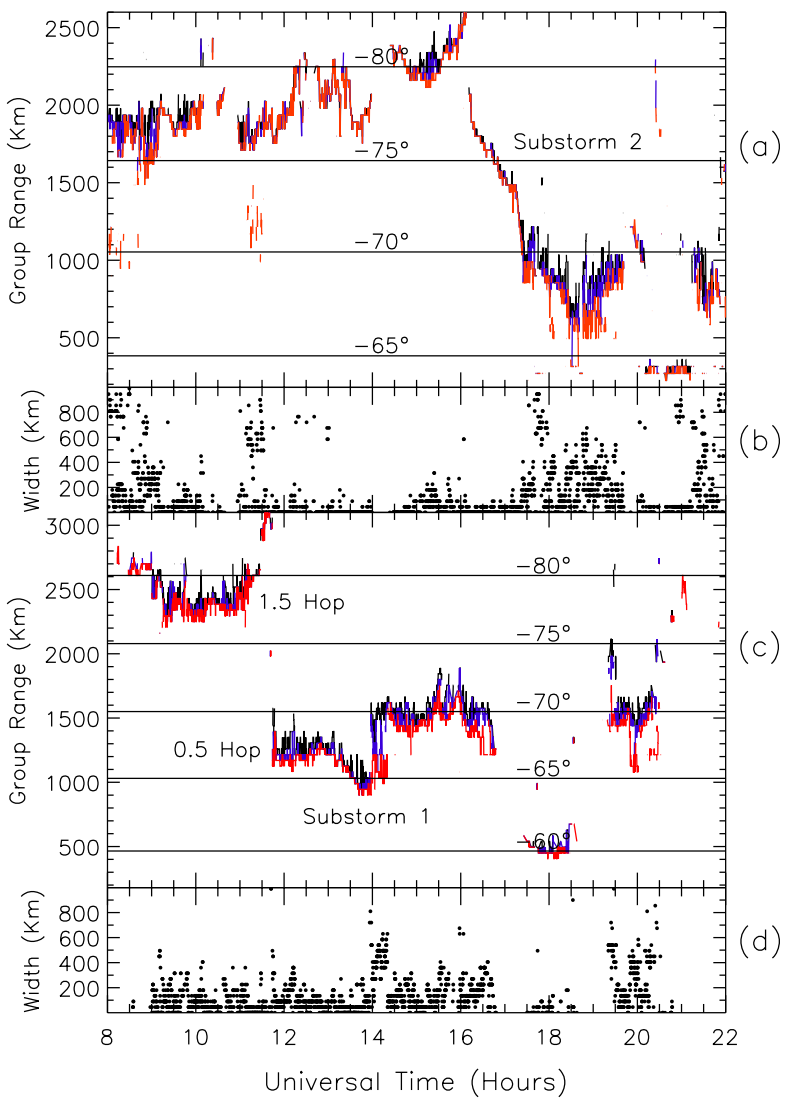

Fig. 4. Range-time plots of the radar spectral width boundaries (SWBs) identified on (a) Halley beam 8 and (c) TIGER beam 4 during 08:00 to 22:00 UT, 1 April 2000. The SWBs are shown for three different values of the spectral width threshold, namely $50 \mathrm{~m} \mathrm{~s}^{-1}$ (red), $100 \mathrm{~m} \mathrm{~s}^{-1}$ (blue), and $150 \mathrm{~m} \mathrm{~s}^{-1}$ (black). The thin horizontal lines represent magnetic latitudes between $-60^{\circ}$ and $-80^{\circ}$. Corresponding differences in the SWB locations using thresholds of $50 \mathrm{~m} \mathrm{~s}^{-1}$ and $150 \mathrm{~m} \mathrm{~s}^{-1}$ are shown in parts (b) and (d).

as bold, black curves in both parts. They fluctuate over $\sim 1^{\circ}$ of latitude on short time scales, though still consistent with the separation of regions with low spectral width $\left(<150 \mathrm{~m} \mathrm{~s}^{-1}\right.$; black and blue) from regions of high spectral width $\left(>150 \mathrm{~m} \mathrm{~s}^{-1}\right.$; green and red).

It would not be possible to explain all of the short-scale fluctuations apparent in Fig. 3 in this paper. Only major variations in the SWB are summarised as follows:

Halley Beam 8: During 08:00 to 15:25 UT the IMF $B_{\mathrm{Z}}$ component was mostly northward, though with brief southward excursions, and the SWB gradually receded poleward. During 08:00 to 13:50 UT the location of the SWB fluctuated rapidly with a succession of poleward contractions up to $\sim 2^{\circ} \Lambda$, but it was mostly located between $-76^{\circ}$ to $-81^{\circ} \Lambda$. During $\sim 13: 50$ to $15: 25$ UT the $B_{\mathrm{z}}$ component was strongly northward and during 14:20 to 15:25 UT the SWB was found further poleward at $\sim-81^{\circ} \Lambda$. A major $B_{\mathrm{Z}}$ southward turning arrived at 15:25 UT (Fig. 2c), and the SWB began to contract poleward, reaching $-85^{\circ} \Lambda$ at 16:10 UT. However, simultaneously, the SWB began a dramatic, $13.5^{\circ}$ equatorward ex- pansion, reaching $-67.5^{\circ} \Lambda$ at 18:35 UT. Beyond this time $B_{\mathrm{Z}}$ was trending northward again, and the SWB began to contract poleward again.

TIGER Beam 4: During 09:00 to 10:45 UT the SWB was located at approximately $-78^{\circ} \Lambda$. Beyond this time the SWB trended poleward, reaching $-85^{\circ} \Lambda$ at 11:35 UT. The SWB suddenly jumped equatorward to $-70^{\circ} \Lambda$ at 11:40 UT. The transition was unrelated to transitions in the solar wind pressure, the nearest major changes occurring at $\sim 10: 15$ and 12:35 UT. Nor was it related to changes in the transmitter frequency which was steady near $11.715 \mathrm{MHz}$. This transition represents a sudden change from a scatter boundary detected via 1.5-hop propagation to a true SWB detected via 0.5 -hop propagation. It occurs because of a reproducible change in HF propagation conditions just past sunset, namely the preferred range gate for 1.5-hop ionospheric scatter recedes to great range because of the familiar post-sunset F-layer height rise (Parkinson et al., 2002a). If there is also a strong equatorward tilt of irregularity production in the auroral oval, a sudden transition between 1.5-hop and 0.5-hop ionospheric scatter can take place. This interpretation is consistent with the behaviour of sea and ionospheric traces determined using ray tracing with the International Reference Ionosphere (Norman et al., 2004).

During 11:45 to $\sim 12: 50$ UT the SWB trended slightly equatorward, but was essentially $-67.5^{\circ} \Lambda$, and fluctuating. Beyond 12:50 UT the SWB expanded equatorward in earnest, reaching $-64^{\circ} \Lambda$ at 13:45 UT. This occurred during the growth, expansion, and early recovery phase of the first substorm with onset at 13:17 UT. At 14:00 UT, the SWB rapidly contracted poleward, reaching $-70^{\circ} \Lambda$ at 14:08 UT. This was still during the recovery phase. The SWB remained at about $-70^{\circ} \Lambda$ until $\sim 15: 15$ UT

A major $B_{\mathrm{Z}}$ southward transition arrived in the dayside ionosphere at 15:25 UT. Shortly after, at about 15:32 UT, the SWB began to expand equatorward from $-73^{\circ} \Lambda$, reaching $-67^{\circ} \Lambda$ at 16:45 UT. This was during the growth phase of the second substorm with onset at 16:51 UT. Beyond 16:51 UT, F-region ionospheric scatter was lost because of changing propagation conditions due to hot particle precipitation (Gauld et al., 2002) and enhanced ionospheric absorption. Large decreases in signal strength were observed by the MQI 30-MHz riometer near to when the ionospheric scatter disappeared in the TIGER FOV. Some of the scatter may also have been lost because hot particle precipitation enhanced the height-integrated Pedersen conductivity, thus suppressing the strength of ionospheric electric fields, and the growth and intensity of ionospheric irregularities (Vickrey and Kelley, 1982; Milan et al., 1999).

The few large spectral widths observed at close ranges during 17:20 to $18: 40 \mathrm{UT}$ at $\sim-60^{\circ} \Lambda$ (Fig. $3 \mathrm{~b}$ ) are thought to be caused by E-region instabilities generated in association with hot electron precipitation, and may not represent a reliable SWB. When continuous ionospheric scatter returned after 19:20 UT, the SWB was found mostly poleward of $-70^{\circ} \Lambda$.

For clarity, the SWBs identified in Fig. 3 are shown separately in Fig. 4 (i.e. without the FITACF parameters). 
However, the SWBs are shown identified using three different values of the spectral width threshold, namely $50 \mathrm{~m} \mathrm{~s}^{-1}$ (red), $100 \mathrm{~m} \mathrm{~s}^{-1}$ (blue), and $150 \mathrm{~m} \mathrm{~s}^{-1}$ (black). Beneath the SWBs for each radar the difference in range for the SWB identified using thresholds of $50 \mathrm{~m} \mathrm{~s}^{-1}$ and $150 \mathrm{~m} \mathrm{~s}^{-1}$ is shown. These numbers are quantitised to the range resolution of the radar $(45 \mathrm{~km})$, yet they still give an indication of the typical width of the SWBs in the radar observations. As can be seen, the SWB can be a broad feature, and its exact location is arbitrarily defined by the choice of the SWB threshold. In this sense, there is an infinite number of SWB locations. However, as discussed in Sect. 2, the threshold used to identify the SWB can be tuned to optimise agreement with the OCB.

The width of the SWB is typically larger in the TIGER nightside observations, as compared with the Halley dayside observations. The distribution function for the width of the SWB in the TIGER observations has a mode value of $\sim 45 \mathrm{~km}$ and a median of $\sim 90 \mathrm{~km}(45-\mathrm{km}$ bins), whereas the Halley observations have a corresponding mode value of $\sim 0 \mathrm{~km}$ and a median of $\sim 45 \mathrm{~km}$. This implies that the dayside SWB is an intrinsically sharper feature in proximity to the ionospheric cusp, whereas the nightside SWB is typically $\sim 1^{\circ} \Lambda$ wide. However, the sharper width of the SWB in the Halley observations occurred because often the SWB was actually a scatter boundary. By this, we mean scatter with large spectral width commenced at some range with no scatter at closer ranges having low spectral width.

Figure 5 shows the distribution functions of spectral widths below (top panel) and above (bottom panel) the SWB, identified using the $\mathrm{C}-\mathrm{F}$ algorithm. The four different colours correspond to results obtained using four different values of the spectral width threshold. The below the SWB distribution, using a threshold of $25 \mathrm{~m} \mathrm{~s}^{-1}$, consists of an isolated peak with mode value $\sim 15 \mathrm{~m} \mathrm{~s}^{-1}\left(10 \mathrm{~m} \mathrm{~s}^{-1}\right.$ bins), but the corresponding above the SWB distribution has two peaks, one at the mode value $\sim 55 \mathrm{~m} \mathrm{~s}^{-1}$, and a secondary peak at $\sim 165 \mathrm{~m} \mathrm{~s}^{-1}$. Conversely, the below the SWB distribution, using a threshold of $150 \mathrm{~m} \mathrm{~s}^{-1}$, contains two peaks, one at the mode value $\sim 55 \mathrm{~m} \mathrm{~s}^{-1}$, and a secondary peak at $\sim 15 \mathrm{~m} \mathrm{~s}^{-1}$. The corresponding above the SWB distribution is dominated by a single peak with mode value $\sim 225 \mathrm{~m} \mathrm{~s}^{-1}$. The results suggest the presence of three or more distinct echo populations amidst a continuum of populations from very low to very large spectral widths.

Figure 6 is an enlargement of Fig. 3b during the time interval 14:00 to 14:35 UT. The bold black on white curves are the SWBs identified using spectral width thresholds of $50 \mathrm{~m} \mathrm{~s}^{-1}$ and $150 \mathrm{~m} \mathrm{~s}^{-1}$. The statistical results of Chisham et al. (2004) imply that the SWB identified using a threshold of $150 \mathrm{~m} \mathrm{~s}^{-1}$ (or more) is a better proxy for the OCB. However, the curves in Fig. 6 confirm that there is no unique spectral width threshold, gradient of spectral width, or SWB location. In fact, there is evidence for multiple, if not an infinite number of SWBs. Prior to 14:20 UT, the two SWBs are well separated and localise a region of scatter with intermediate spectral widths (mode $>50 \mathrm{~m} \mathrm{~s}^{-1}$ ), which also contain isolated

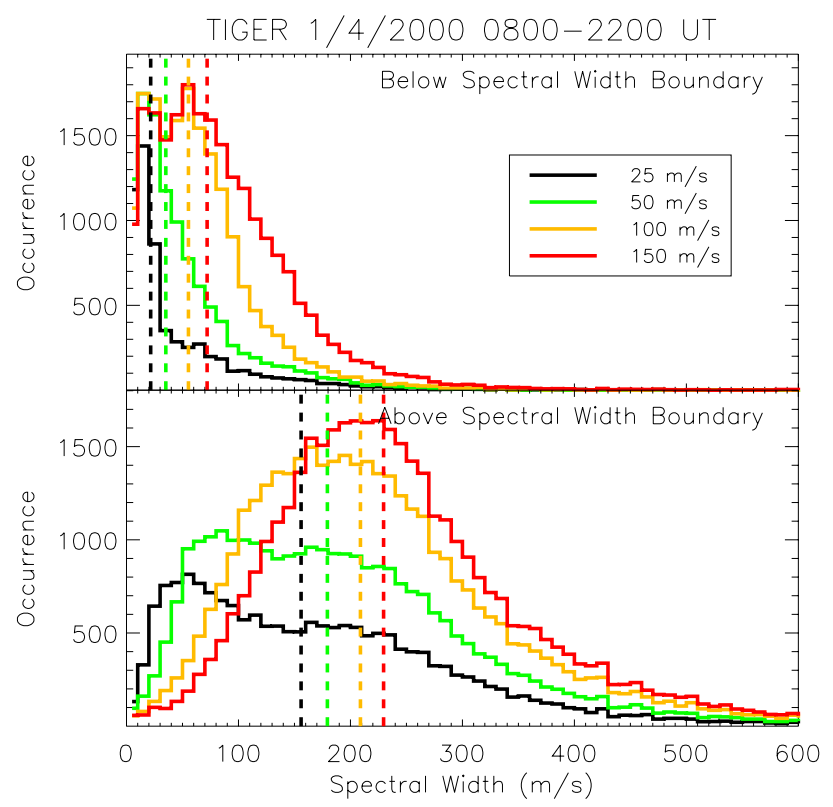

Fig. 5. Spectral width distributions for echoes measured on TIGER beam 4 during 08:00 to 22:00 UT, 1 April 2000. The distributions below (top panel) and above (bottom panel) the spectral width boundary (SWB) were identified using spectral width thresholds of $25 \mathrm{~m} \mathrm{~s}^{-1}$ (black), $50 \mathrm{~m} \mathrm{~s}^{-1}$ (green), $100 \mathrm{~m} \mathrm{~s}^{-1}$ (orange), and $150 \mathrm{~m} \mathrm{~s}^{-1}$ (red). The corresponding vertical chains indicate the median values of the distributions.

regions with very low spectral width (mode $\sim 15 \mathrm{~m} \mathrm{~s}^{-1}$ ). In principal, several simultaneous SWBs can be identified using a spectral width threshold of $50 \mathrm{~m} \mathrm{~s}^{-1}$. Another region of intermediate spectral width exists above the $150 \mathrm{~m} \mathrm{~s}^{-1}$ boundary near 14:04 to 14:06 UT. After 14:21 UT the SWBs using thresholds of $50 \mathrm{~m} \mathrm{~s}^{-1}$ and $150 \mathrm{~m} \mathrm{~s}^{-1}$ are aligned to within $\sim 1^{\circ} \Lambda$, and they separate a region with very low spectral width (mode $\sim 15 \mathrm{~m} \mathrm{~s}^{-1}$ ) from a region with very large spectral width (mode $>200 \mathrm{~m} \mathrm{~s}^{-1}$ ).

Clearly, Figs. 5 and 6 prove the existence of genuine, multiple SWBs. Spatial structure in the instantaneous SWB may be very complicated, with fluctuations in longitude, as well as latitude, thus causing apparent multiple SWBs along the same beam (e.g. "s-shaped" features in the boundary). However, this does not explain the present observations.

\subsection{Comparison with DMSP satellite measurements}

Identifications of the ionospheric cusp along the fixed local time orbits of the DMSP satellites were not coincident with the Halley radar FOV during 08:00 to 22:00 UT on 1 April 2000. Here we focus on the less well understood behaviour of the nightside SWB measured by the TIGER radar. Nevertheless, we report our results in the context of the Halley dayside observations, thereby providing possible clues about noon-midnight coupling in the ionosphere and magnetosphere.

Figure 7a presents SWB data closely related to that shown for TIGER in Fig. 4b, except now the SWBs have been 


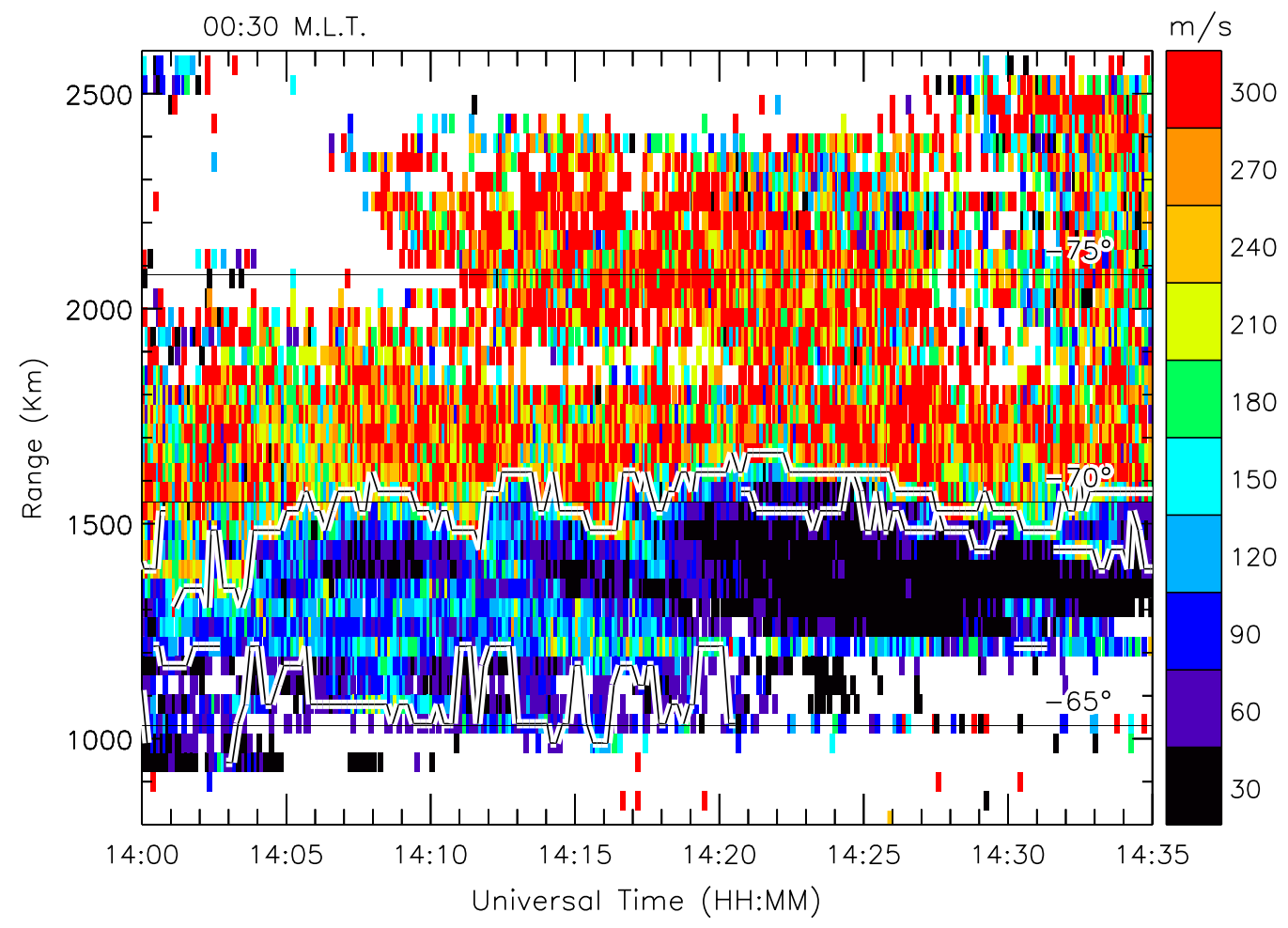

Fig. 6. Range-time plots of the radar spectral widths measured on TIGER beam 4 at 6-s time intervals during 14:00 to 14:35 UT on 1 April 2000. Black on white fluctuating curves delineate the SWBs identified using the C-F algorithm with thresholds of $50 \mathrm{~m} \mathrm{~s}^{-1}$ and $150 \mathrm{~m} \mathrm{~s}^{-1}$.

determined on all sixteen beams using a spectral width threshold of $150 \mathrm{~m} \mathrm{~s}^{-1}$, and then sorted according to magnetic latitude. This reveals physically meaningful variations in SWB shape, more effectively than when the results are sorted according to group range. The SWB identified on each beam is colour coded with the westerly beams (beams 0,1 , ...) represented by cold, blue colours and the easterly beams (beams $15,14, \ldots$ ) by warm, red colours. By analogy to the shape of the auroral oval, we expect that the SWB shape will have an equatorward tilt before midnight; it will be roughly $L$-shell aligned near midnight, and then it will have a poleward tilt after midnight.

Figure $7 \mathrm{~b}$ shows the standard deviation (sigmas) of the SWB identified on all 16 beams and calculated using a running time window of $192 \mathrm{~s}$ (two full scans). This gives a measure of how much the SWB location changes in magnetic latitude with MLT during individual scans. The results plotted in Fig. $7 \mathrm{~b}$ can be grouped into three broad intervals: (1) the sigmas were large, often $>2^{\circ} \Lambda$ during $\sim 08: 00$ to 11:30 UT because of a large equatorward tilt of the SWB with MLT (cf. Fig. 1, 10:04:04 UT scan), (2) the sigmas were small, mostly $<2^{\circ} \Lambda$ during $11: 45$ to $16: 51$ UT when the SWB was nearly $L$-shell aligned, and (3) the sigmas were somewhat larger again during 19:20 to 20:35 UT, when a poleward tilt in the SWB was probably beginning to emerge.

The most striking feature in Fig. 7a is the rapid variation of the SWB with beam number during the interval 09:00 to 11:30 UT. The SWB was consistently observed poleward of $-78^{\circ} \Lambda$ on the most westerly beams (violet), and equator- ward of $\sim-72^{\circ} \Lambda$, on the most easterly beams (red). Numerous small spatial and temporal fluctuations were superimposed on this trend, but usually only coherent over a small number of beams. On average, the instantaneous SWB had an equatorward tilt of $>2.4^{\circ} \Lambda \mathrm{h}^{-1}$ of MLT in the $\sim 20: 00$ to 22:00 MLT sector. However, the equatorward tilt became an artifact caused by detection of a scatter boundary during the final stages of this interval.

During the interval 11:45 to $\sim 14: 10$ UT, the SWB on the most easterly beams (orange and red) were still located at lower latitude, but this is partly because these results were plotted last, and are superimposed on the results for the westerly beams. In fact, results to be presented in the next section show that the SWB was located at a similar latitude on all beam numbers during this interval. This implies that the instantaneous SWB was roughly $L$-shell aligned in the midnight sector, $\sim 22: 00$ to 02:00 MLT. Again, there were numerous small spatial and temporal fluctuations, but usually coherent across all 16 beams on longer time scales.

After $\sim 14: 10$ UT there tended to be a slight equatorward tilt of the SWB, persisting in the morning sector, 00:00 to 04:00 MLT. However, especially after 19:20 UT ( 05:00 MLT), the SWB was sometimes at a higher latitude on the most easterly beams (red), the reverse of the situation occurring before midnight. This suggests that a poleward tilt in the SWB was beginning to emerge near dawn.

The 10 bold vertical lines superimposed in Fig. 7a represent the location of the auroral oval identified from energy spectra of precipitating particles measured on board the 


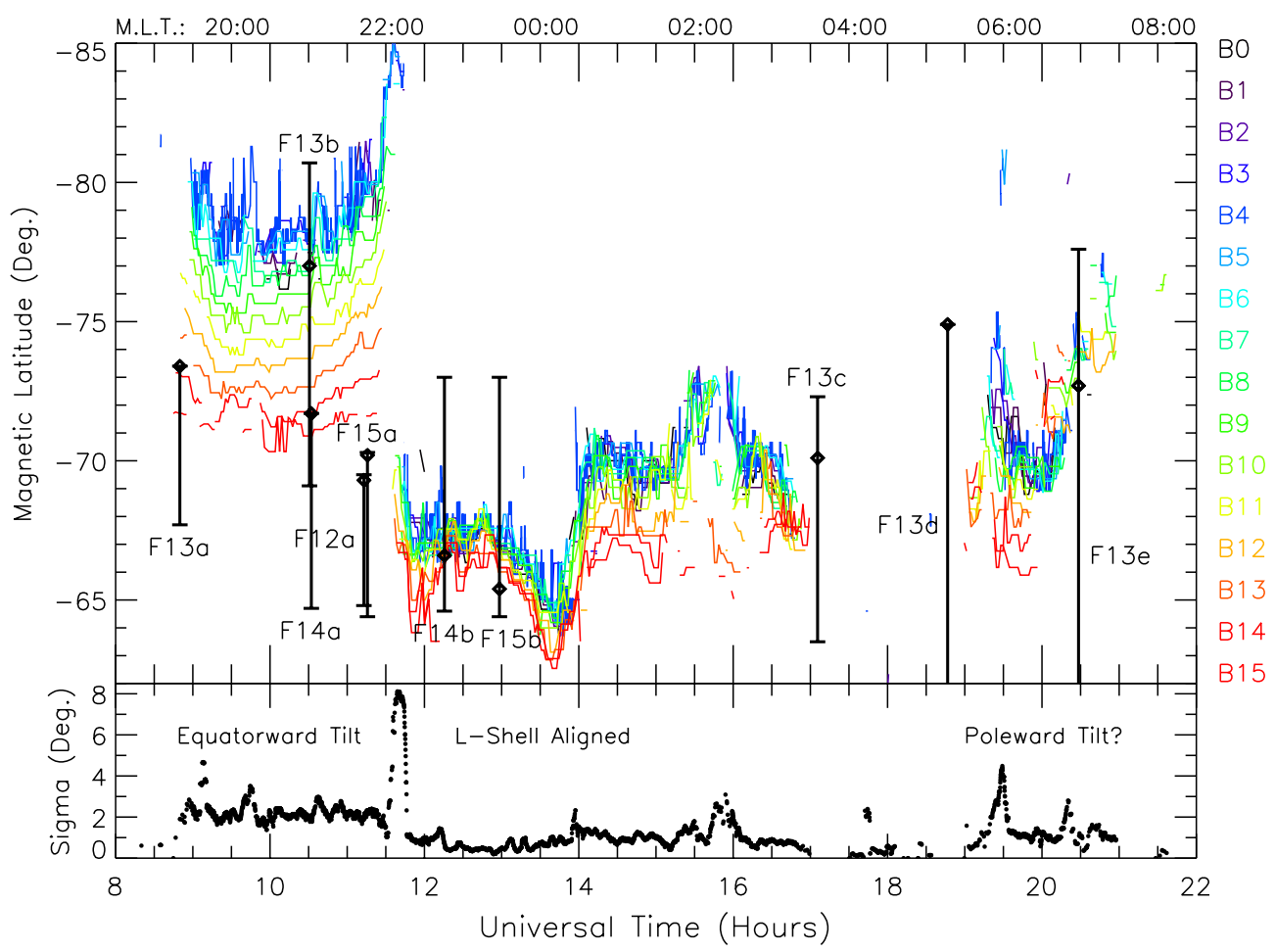

Fig. 7. (a) Magnetic latitude vs. UT plot of the radar SWB identified on all 16 beams of the TIGER radar during 08:00 to 22:00 UT, 1 April 2000. The SWB on each beam is colour coded (right) using black for beam 0 , violet for beam $1, \ldots$, and red for beam 15 . The 10 bold, vertical bars with diamonds represent the location of the auroral oval identified from spectrograms of precipitating particles measured on board the DMSP satellites (symbols explained in the text). (b) The standard deviation of the SWB identified on all 16 beams using a running time window of $192 \mathrm{~s}$ (two full scans).

DMSP satellites (see Table 1). The horizontal bars merely emphasise the equatorward and poleward limits of particle precipitation. The bold diamonds mark our estimates of the poleward limit of hot particle precipitation most likely to strongly enhance the E-region conductivity. The diamonds are placed where significant fluxes in both electron and ion precipitation became colder than $\sim 1 \mathrm{keV}$ and $10 \mathrm{keV}$, respectively.

Each DMSP pass has been assigned a unique identifier, F13a, F13b, etc., in Fig. 7a and Table 1. Note the geodetic longitude of the TIGER radar is $147.2^{\circ} \mathrm{E}$, and its boresight points due south. Knowing the approximate geodetic co-ordinates of every observation cell in the TIGER FOV, it was possible to identify the beam number closest to each DMSP pass at the instant when it crossed the poleward edge of the auroral oval. Recall that the DMSP poleward edges provide an independent proxy for the OCB.

Whilst DMSP poleward edges agree with the location of the radar SWBs on a statistical basis (Chisham et al., 2004), during this particular study interval, only a few of the DMSP poleward edges agreed with the SWBs. However, the two kinds of measurement are never made exactly coincident in space and time, so we must allow for rapid variations in the auroral oval boundaries and SWB locations with MLT (i.e. tilts in space) and UT (i.e. fluctuations in time), as well as changes in HF propagation conditions.
The F13a poleward edge identified at 08:49:55 UT was located at $-73.4^{\circ} \Lambda$, closest to beam 11 (yellow). The SWB was identified at $\sim-77^{\circ} \Lambda$ on beam 11 at this time. However, this was a scatter boundary and a genuine SWB was observed at $\sim-74^{\circ} \Lambda$ after 09:00 UT when the operating frequency decreased. The transition shown in Fig. 7a seems more gradual because of median filtering. The SWB trended poleward during 09:30 to 11:30 UT. When allowing for the trend in time and possible latitudinal errors $\left(\sim 1^{\circ} \Lambda\right)$, the SWB and poleward edge were probably in very good agreement.

Remarkably, the F13b poleward edge identified at 10:30:38 UT was located at $-80.7^{\circ} \Lambda$, whereas an F14a poleward edge, identified a mere $88 \mathrm{~s}$ later at 10:32:06 UT, was located at $-71.7^{\circ} \Lambda$. However, the F13b and F14a poleward edges were well separated, identified closest to beams 3 (dark blue) and 15 (red), respectively. Online energy spectra for the F13b pass suggest that the poleward limit of hot particle precipitation was located near $\sim-77.0^{\circ} \Lambda$. The nearest SWB identifications were located at $-77.8^{\circ} \Lambda$ on beam 3 and $-70.9^{\circ} \Lambda$ on beam 15 . Thus, the F13b hot particle boundary and the F14a poleward edge were coincident with the radar SWB, well within experimental error. These results also confirm a large equatorward tilt of the SWB and OCB before midnight.

The next two passes (F12a and F15a) placed the poleward edges at $11: 12: 58$ and $11: 15: 43 \mathrm{UT}$ at $-69.5^{\circ}$ and $-70.3^{\circ} \Lambda$, 
Table 1. Nightside auroral oval boundaries superimposed in Fig. 7a.

\begin{tabular}{|c|c|c|c|c|c|c|}
\hline DMSP & UT & Geodetic Longitude & MLT (Hours) & Magnetic Latitude & Boundary & Nearest Beam \\
\hline \multirow[t]{3}{*}{ F13a } & $08: 49: 55$ & $155.4^{\circ}$ & 20.7 & $-73.4^{\circ}$ & $\mathrm{b} 5 \mathrm{e}$ & 11 \\
\hline & $08: 49: 55$ & $155.4^{\circ}$ & 20.7 & $-73.4^{\circ}$ & $\mathrm{h} / \mathrm{c}$ & 11 \\
\hline & 08:52:02 & $150.6^{\circ}$ & 19.8 & $-67.7^{\circ}$ & b1e & 10 \\
\hline \multirow[t]{3}{*}{ F13b } & $10: 30: 38$ & $133.7^{\circ}$ & 20.4 & $-80.7^{\circ}$ & b5e & 3 \\
\hline & $10: 31: 54$ & $129.8^{\circ}$ & 19.5 & $-77.0^{\circ}$ & $\mathrm{h} / \mathrm{c}$ & $<0$ \\
\hline & $10: 34: 21$ & $124.5^{\circ}$ & 18.8 & $-69.1^{\circ}$ & b1e & $<0$ \\
\hline \multirow[t]{3}{*}{$\mathrm{F} 14 \mathrm{a}$} & $10: 32: 06$ & $173.3^{\circ}$ & 0.2 & $-71.7^{\circ}$ & b5e & 15 \\
\hline & $10: 32: 06$ & $173.3^{\circ}$ & 0.2 & $-71.7^{\circ}$ & $\mathrm{h} / \mathrm{c}$ & 15 \\
\hline & $10: 35: 03$ & $166.2^{\circ}$ & 22.9 & $-64.7^{\circ}$ & b1i & $>15$ \\
\hline \multirow[t]{3}{*}{$\mathrm{F} 12 \mathrm{a}$} & $11: 12: 58$ & $153.9^{\circ}$ & 22.6 & $-69.5^{\circ}$ & b5i & 12 \\
\hline & 11:13:03 & $153.7^{\circ}$ & 22.6 & $-69.3^{\circ}$ & $\mathrm{h} / \mathrm{c}$ & 12 \\
\hline & $11: 14: 35$ & $150.9^{\circ}$ & 19.4 & $-64.8^{\circ}$ & b1i & 12 \\
\hline \multirow[t]{3}{*}{$\mathrm{F} 15 \mathrm{a}$} & $11: 15: 43$ & $168.6^{\circ}$ & 0.3 & $-70.3^{\circ}$ & $\mathrm{b} 5 \mathrm{i}$ & $>15$ \\
\hline & $11: 15: 46$ & $168.5^{\circ}$ & 0.2 & $-70.2^{\circ}$ & $\mathrm{h} / \mathrm{c}$ & $>15$ \\
\hline & 11:18:03 & $163.5^{\circ}$ & 23.3 & $-64.4^{\circ}$ & b1e & $>15$ \\
\hline \multirow[t]{3}{*}{$\mathrm{F} 14 \mathrm{~b}$} & $12: 15: 34$ & $143.6^{\circ}$ & 22.7 & $-73.0^{\circ}$ & $\mathrm{n} / \mathrm{a}$ & 6 \\
\hline & $12: 17: 44$ & $139.4^{\circ}$ & 20.6 & $-66.6^{\circ}$ & $\mathrm{h} / \mathrm{c}$ & 0 \\
\hline & $12: 18: 20$ & $138.4^{\circ}$ & 21.9 & $-64.6^{\circ}$ & b1i & $<0$ \\
\hline \multirow[t]{3}{*}{$\mathrm{F} 15 \mathrm{~b}$} & $12: 58: 20$ & $141.2^{\circ}$ & 23.1 & $-73.0^{\circ}$ & $\mathrm{n} / \mathrm{a}$ & 4 \\
\hline & 13:00:48 & $136.5^{\circ}$ & 22.4 & $-65.4^{\circ}$ & $\mathrm{h} / \mathrm{c}$ & $<0$ \\
\hline & 13:01:07 & $136.0^{\circ}$ & 22.3 & $-64.4^{\circ}$ & b1e & $<0$ \\
\hline \multirow[t]{3}{*}{$\mathrm{F} 13 \mathrm{c}$} & $17: 05: 34$ & $174.4^{\circ}$ & 7.0 & $-72.3^{\circ}$ & b5e & $>15$ \\
\hline & $17: 04: 53$ & $176.5^{\circ}$ & 6.8 & $-72.3^{\circ}$ & $\mathrm{h} / \mathrm{c}$ & $>15$ \\
\hline & $17: 02: 55$ & $181.3^{\circ}$ & 6.6 & $-63.5^{\circ}$ & $\mathrm{n} / \mathrm{a}$ & $>15$ \\
\hline \multirow[t]{3}{*}{ F13d } & $18: 46: 39$ & $151.6^{\circ}$ & 6.5 & $-74.9^{\circ}$ & $\mathrm{b} 5 \mathrm{e}$ & 9 \\
\hline & $18: 46: 39$ & $151.6^{\circ}$ & 6.5 & $-74.9^{\circ}$ & $\mathrm{h} / \mathrm{c}$ & 9 \\
\hline & $18: 41: 47$ & $161.0^{\circ}$ & 6.3 & $-57.8^{\circ}$ & b1e & $>15$ \\
\hline \multirow[t]{3}{*}{$\mathrm{F} 13 \mathrm{e}$} & $20: 28: 27$ & $126.5^{\circ}$ & 5.2 & $-77.6^{\circ}$ & b5i & 0 \\
\hline & $20: 27: 00$ & $129.9^{\circ}$ & 5.5 & $-72.7^{\circ}$ & $\mathrm{h} / \mathrm{c}$ & $<0$ \\
\hline & $20: 23: 06$ & $136.4^{\circ}$ & 5.8 & $-58.9^{\circ}$ & b1i & $<0$ \\
\hline
\end{tabular}

respectively. These identifications were made closest to beams 12 (orange) and 15 (red), respectively. Closest to the time of the satellite passes, beam 12 placed the SWB at $-75.1^{\circ} \Lambda$ and beam 15 at $-71.6^{\circ} \Lambda$. The results for F15a probably agree within experimental error, but the results for the F12a pass do not.

Note that the SWBs identified on all beams were contracting poleward at this time, just prior to a large and sudden equatorward jump in the SWB at 11:40 UT to $-70^{\circ} \Lambda$ (beam 4). The results for the F12a pass disagreed because the SWB had evolved into a scatter boundary detected via 1.5 -hop propagation preceding 11:40 UT. The true SWB was probably located at the range of 1.0-hop sea echoes (not shown). However, the poleward edge identified during the F15a pass, just $165 \mathrm{~s}$ later, showed better agreement with the SWB observed on beam 15 because the same group ranges mapped to significantly lower magnetic latitude.
Automatic analysis of the F14b pass at 12:15:34 UT placed the poleward edge at $-73.0^{\circ} \Lambda$ in the spectrogram of precipitating ions, yet $-67.0^{\circ} \Lambda$ in the spectrogram of precipitating electrons. The spectrograms were very complicated, with a succession of drops in electron and ion fluxes, and without access to pitch-angle distributions, the true location of the OCB is uncertain. However, the preceding hours were dominated by quiet $B_{\mathrm{Z}}$ northward conditions. Drops to cold plasma populations are common in the plasma sheet during and shortly after these conditions (Wing and Newell, 2002; Stenuit et al., 2002). Hence, we place the OCB at $-73.0^{\circ} \Lambda$, an identification made closest to beam 6 which placed the SWB far equatorward at $-67.6^{\circ} \Lambda$. The SWB was actually located closer to the poleward limit of hot particle precipitation (diamond).

Next, the F15b pass at 12:58:20 UT placed the poleward edge of the auroral oval at $-73.0^{\circ} \Lambda$. The low energy ion 
detector $(<1 \mathrm{keV})$ on board the F15 satellite was not operating correctly, but the conditions and available data were similar to those of the previous F14b spectra, suggesting that cold plasma sheet ions also extended further poleward to $-73.0^{\circ} \Lambda$. This identification was made closest to beam 4 , which near to this time, measured the SWB far equatorward at $-66.8^{\circ} \Lambda$. Again, the SWB was located closer to the approximate poleward limit of hot particle precipitation, $-65.4^{\circ} \Lambda$.

The next two F13 passes (c and d) placed the poleward edges at 17:03:33 and 18:46:39 UT at $-72.3^{\circ}$ and $-74.9^{\circ} \Lambda$, respectively. Unfortunately, these dawn sector identifications were made during the expansion and recovery phases of the second, moderate substorm which caused the loss of most ionospheric scatter. However, again, the available observations imply that the SWB was located much further equatorward. Note that the F13c poleward edge was identified to the east of beam 15 when the SWB may have been located further poleward than implied by Fig. 7a, because of the eastward orientation of the FOV. Similarly, the F13d poleward edge was closest to beam 9 when the SWB may have been located further poleward because of the expected poleward tilt of the OCB. Also, the SWB may have receded further poleward because of magnetotail reconnection during the recovery phase. Nevertheless, overall, our observations suggest that the SWBs were probably located far equatorward of the OCBs.

The final F13e pass at 20:28:27 UT placed the poleward edge at $-77.6^{\circ} \Lambda$. This identification was made closest to beam 0 . Unfortunately, the SWB was poorly defined on the western beams at this time, but the trends shown in Fig. 6a suggest that the DMSP poleward edge was at most $\sim 2^{\circ}$ further poleward of the SWB. Thus, the DMSP poleward edge and SWB may have agreed within experimental error. However, as with previous passes, the SWB was actually located closer to the poleward limit of hot particle precipitation, $-72.7^{\circ} \Lambda$.

\subsection{Spectral width boundary shape}

The format used to present the multi-beam SWB data in Fig. 7 was only useful for revealing large variations in SWB shape because the curves for different beams were superimposed. Figure 8 reveals the detailed evolution of SWB shape for the Halley and TIGER radars during 08:00 to 22:00 UT on 1 April 2000. The SWBs were estimated using the C-F algorithm and a spectral width threshold of $150 \mathrm{~m} \mathrm{~s}^{-1}$. All the points shown have been averaged over 15-min bins to reduce clutter in the diagram, and then mapped to co-ordinates consisting of MLT and AACGM latitude. As explained in the caption, a different colour was used for results obtained in each 15-min bin past the hour. UT at Halley $(\mathrm{H})$ and TIGER (T) are annotated around the perimeter. Keep in mind that these results do not show an instantaneous "snapshot" of SWB shape at all MLT. Rather, space and time variations are mixed because of the limited longitudinal coverage of both radars.

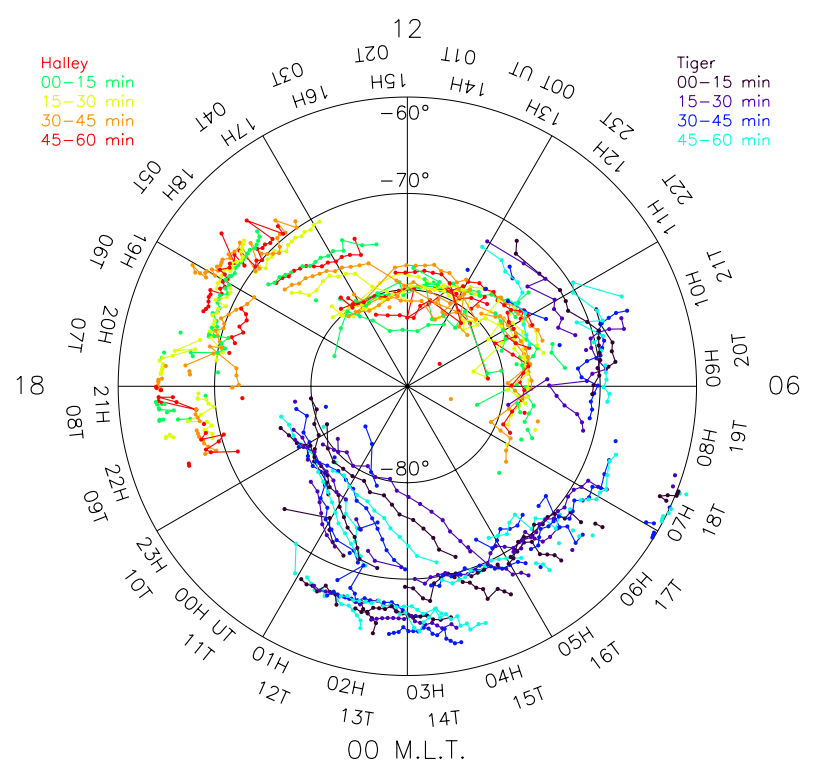

Fig. 8. SWBs for Halley and TIGER radar full scans during 08:00 to 22:00 UT on 1 April 2000. The results have been mapped to co-ordinates consisting of MLT and AACGM latitude. The SWBs have been averaged over 15-min intervals, and are color coded as follows: Halley 00-15 $\mathrm{min}$ (green), 15-30 min (yellow), 30$45 \mathrm{~min}$ (orange), and 45-60 $\mathrm{min}$ (red) past the hour, and TIGER 00-15 min (black), 15-30 min (purple), 30-45 min (blue), and 45$60 \mathrm{~min}$ (aqua) past the hour.

Figure 9 represents an alternative method of portraying relative variations in SWB shape. For brevity, only the more subtle variations measured by the Halley radar are shown. For each 5-min interval, the magnetic latitude of the SWB identified on each beam was averaged. Up to 16 averages were then available to calculate the average magnetic latitude of the SWB across the entire FOV. The calculations were performed in this way to prevent the high-time resolution beam 8 results biasing the results. Next, the difference between the average latitude of the SWB for each beam and the average latitude of the SWB across the entire FOV was calculated. These are the numbers colour coded in Fig. 9.

The way the differences in Fig. 9 change with beam number indicates the "instantaneous" shape of the SWB, assuming it was stationary during the 5-min averaging time. Note that if the SWB forms a spatial bay extending to higher latitudes in the radar FOV, the differences will be negative (cold colours) on the central beams and positive (warm colours) on the eastern and western-most beams. Conversely, if the SWB forms a spatial bulge extending to lower latitudes, the differences will be positive on the central beams, and negative towards the edge beams.

It would be impractical to explain all of the numerous, complicated spatial and temporal fluctuations in Figs. 8 and 9. Keeping in mind that the colour key in Fig. 9 ranges over $\sim 3^{\circ} \Lambda$, only the largest variations are summarised as follows:

The locus of curves in Fig. 8 reveals that the Halley dayside SWB had an equatorward tilt toward the east at 


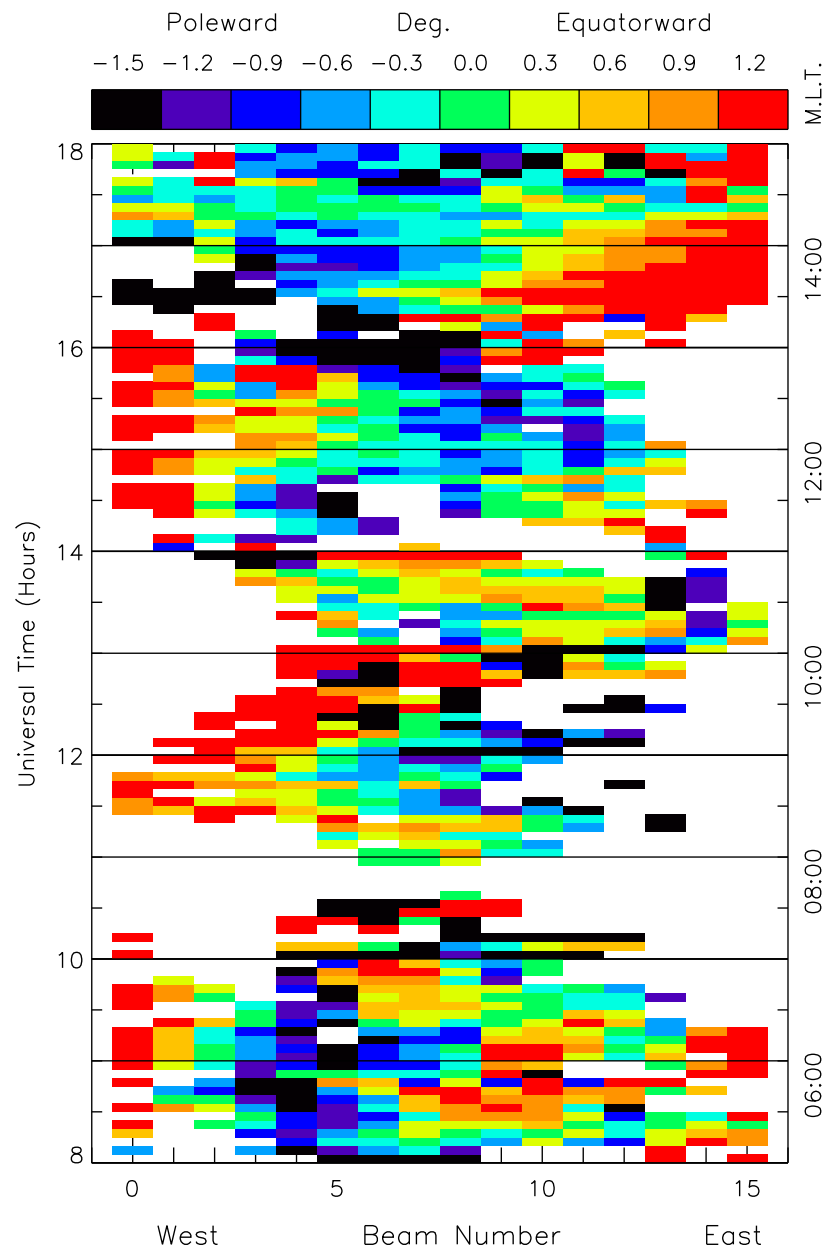

Fig. 9. SWB shape versus UT for the Halley radar during 08:00 to 18:00 UT, 1 April 2000. The colour scale gives the difference between the magnetic latitude of the SWB on each beam versus the average magnetic latitude of the SWB across all beams. The calculations were performed at 5-min intervals. See the text for further explanation.

dawn ( 06:00 MLT), and a subsequent poleward tilt toward the east beyond 09:00 MLT. Hence, there was an apparent equatorward bulge during these quiet, $B_{\mathrm{y}}$ negative conditions. In the 10:00 to 14:00 MLT sector (i.e. noon) the variations in SWB shape were complicated, with evidence for equatorward bulges in some scans (Fig. 9; 13:45 to 14:00 UT), and poleward bays in others (15:45 to $16: 15$ UT). Perhaps these alternating bulges and bays were somehow related to magnetic reconnection occurring under $B_{\mathrm{Z}}$ northward conditions (cf. Chisham et al., 2001; Pinnock and Rodger, 2001).

Figure 9 facilitates a more accurate timing of these changes in Halley SWB shape. During 08:00 to 10:35 UT the SWB had an equatorward tilt toward the east. Then, during $\sim 10: 55$ to 13:05 UT an equatorward tilt toward the west emerged. Again, there was a distinct equatorward tilt toward the west during $\sim 14: 20$ to $15: 45 \mathrm{UT}$, preceding the formation of a transient poleward bay during $15: 45$ to $16: 20 \mathrm{UT}$ (the green curve near noon in Fig. 8). During $\sim 16: 20$ to 17:15 UT, the SWB had a strong equatorward bulge toward the east in the post-noon sector under $B_{\mathrm{Z}}$ strongly southward, $B_{\mathrm{y}}$ negative conditions.

During the remainder of the study interval, there were many fluctuations in SWB shape, but it was approximately $L$-shell aligned during 18:00 to 19:40 UT ( 16:00 MLT) when $B_{\mathrm{z}}$ was trending northward again.

Figure 8, and the equivalent of Fig. 9 for TIGER revealed the detailed behaviour of the nightside SWB:

From 08:55 to 11:40 UT ( 19:00 to 02:00 MLT) there was a large, distinct variation in the SWB location with beam number (cf. Fig. 7a). In the pre-midnight sector, the SWB was tilted poleward towards the west, and equatorward towards the east. The SWB evolved from a true SWB to a group delay aligned scatter boundary just prior to 11:40 UT. During 11:45 to $13: 40$ UT ( $\sim 22: 00$ to 04:00 MLT) the SWB shape was initially magnetic $L$-shell aligned to first order. However, the SWB shape developed a significant equatorward tilt toward the east post midnight, during 13:45 to 16:10 UT. This equatorward tilt was stronger on the easternmost beams from the start of the recovery phase of the first minor substorm (13:32 UT).

A second substorm caused the loss of ionospheric scatter during $\sim 16: 50$ to 19:20 UT. When scatter subsequently returned near dawn, the TIGER SWB was initially located slightly equatorward toward the east. Otherwise, there was no striking SWB shape near dawn.

In summary, the preceding analysis illustrates the potential of SuperDARN to reveal ongoing variability in the shape of the SWB, and thus at times, perhaps also the OCB.

\section{Discussion and interpretation}

4.1 Substorm-related changes in the spectral width boundary

First, we interpret the observed behaviour of the dayside SWB in the context of the expanding/contracting model of high-latitude convection, and discuss the way in which the behaviour of the nightside SWB is organized according to substorm phase.

Here the onset of the first, small substorm $(-122 \mathrm{nT})$ occurred at 13:17 UT (Fig. 2e), near to when the $B_{\mathrm{z}}$ component swung northward after $B_{\mathrm{Z}}$ was $\sim-3 \mathrm{nT}$ for $\sim 1 \mathrm{~h}$ (Fig. 2c). The Halley radar measured an $\sim 4^{\circ} \Lambda$ equatorward expansion of the dayside SWB throughout the substorm growth and expansion phases (Figs. 3a and 4a). The Halley dayside response was more obvious when "sea echoes" were used in the C-F algorithm (i.e. some of these echoes were actually from the ionosphere). The TIGER radar also measured an $\sim 3^{\circ} \Lambda$ equatorward expansion of the SWB during the growth, expansion, and recovery phases (Figs. $3 \mathrm{~b}$ and $4 \mathrm{c}$ ). This equatorward expansion was delayed by several tens of minutes after that observed by the Halley radar. The TIGER radar measured a rapid poleward contraction of the nightside 
SWB at 14:00 UT during the recovery phase of the first substorm. Perhaps the dayside SWB measured by Halley contracted simultaneously, or shortly after, but the absence of echoes detected by Halley makes this difficult to tell.

The growth phase of the second moderate substorm $(-413 \mathrm{nT})$ began near 15:25 UT, the arrival time of a major, step-like $B_{\mathrm{Z}}$ southward transition (Parkinson et al., 2002c). Expansion onset occurred at 16:51 UT when $B_{\mathrm{Z}}$ was gradually swinging further southward, and the start of the recovery phase, 17:56 UT, may have been coincident with the arrival of a $B_{\mathrm{Z}}$ northward spike. $B_{\mathrm{z}}$ continued to trend northward during the remainder of the recovery phase, and beyond.

The Halley line-of-sight velocity data revealed an unambiguous response of the noon-sector ionosphere to the $B_{\mathrm{Z}}$ southward transition at 15:25 UT (Parkinson et al., 2002c). However, depending on the algorithm used to estimate the nightside SWB, the TIGER observations did not show it expanding equatorward until 15:35 UT. This time delay may represent the point beyond which the effects of enhanced dayside reconnection superceded the effects of magnetotail reconnection within the nightside ionosphere. Such observations must be understood in the context of detailed modeling of magnetospheric processes, including dayside reconnection and substorm-related activity.

The Halley radar initially observed a band of scatter contracting poleward at 15:25 UT. However, an enlargement of Fig. 3a shows that scatter with low power began to expand equatorward at the same time. This bifurcation resembles the radar and auroral imager signatures presented by Milan et al. (2000) for a similar $B_{\mathrm{Z}}$ southward transition. Overall, the Halley scatter underwent a dramatic equatorward expansion from $-81^{\circ} \Lambda$ at $15: 25 \mathrm{UT}$ to $-67.5^{\circ} \Lambda$ at 18:35 UT, before contracting poleward beyond this time. The rapid expansion of the dayside polar cap ionosphere $\left(\sim 4.7^{\circ} \Lambda \mathrm{h}^{-1}\right)$ was probably caused by the accumulation of open magnetic flux generated by intense dayside merging. The nightside reconnection rate must have been slower than the dayside reconnection rate until 18:35 UT.

The behaviour of the dayside SWB during the second moderate substorm was similar to that during the first minor substorm, namely an equatorward expansion during the growth and expansion phases of the substorm, followed by a poleward contraction during the recovery phase. The TIGER observations suggest that the response of the nightside SWB was similar, except that the equatorward expansion was delayed during the growth and expansion phases. The nightside SWB expanded equatorward during the growth phase until 16:51 UT when most ionospheric scatter was lost. It is probable that the SWB continued to expand further equatorward after 16:51 UT, and then rapidly contracted poleward sometime during the recovery phase, 17:57 to 19:20 UT. If the close range scatter observed during 17:20 to 18:40 UT (Figs. 3b and 4c) represented the peak equatorward expansion of the SWB, it implies that the poleward contraction of the nightside SWB was more rapid than the preceding contraction of the dayside SWB.
The previous interpretation is supported by the results of Parkinson et al. (2003b) ${ }^{1}$. They investigated how well the nightside SWB agreed with the poleward edge of the auroral oval during two nights which encompassed 4 substorms. During 3 of the substorms, the SWB was observed to gradually expand equatorward during the expansion phase, and then rapidly contract poleward during the recovery phase. For the remaining small substorm, $B_{\mathrm{z}}$ was weakly southward, and the post-midnight SWB was trending poleward before and during the substorm.

The behaviour of the nightside SWB during substorms, especially the rapid poleward contractions, may represent the time when the effects of nightside reconnection superceded the effects of dayside reconnection. However, the behaviour may also be related to the dynamics of particle precipitation during substorms. For example, the aurora are well known to rapidly expand poleward at expansion onset in the postmidnight sector. These poleward aurora migrate to earlier MLT, a phenomenon known as "westward traveling surge". Perhaps the rapid poleward contractions of the pre-midnight SWB are caused by the arrival of hot particle precipitation initiated somewhat earlier. This idea will be tested when coincident global satellite observations of auroral emissions become available.

The preceding observations suggest that the behaviour of the radar SWBs were closely related to expansions and contractions of the OCB in response to the combined effects of changing day- and nightside reconnection rates, including substorm processes. It seems that the radar SWB behaves in a similar way to the OCB in many MLT sectors, and for various levels of geomagnetic activity. However, our observations suggest that the SWB is often a better proxy for the poleward limit of hot particle precipitation (e.g. Fig. 7 and others not shown).

\subsection{Formation of the spectral width boundary}

Previous studies have shown the nightside SWB is often coincident with the OCB (Lester et al., 2001; Parkinson et al., 2002b, 2003b ${ }^{1}$; Chisham et al., 2004), and often behaves in a similar way, but it is clearly a different entity. The work of Woodfield et al. (2002a, b, c) suggests that the nightside SWB is often found equatorward of the OCB in the postmidnight sector, and the results of Parkinson et al. (2003b) ${ }^{1}$ support this view. The present results (i.e. Fig. 7a) also imply that the SWB can be found equatorward of the OCB in the pre-midnight sector, as well as the post-midnight sector. What then, causes the formation of a SWB?

Whilst not the focus of this study, we first briefly consider the possible drivers of the electric field fluctuations causing the large spectral widths. Large-scale variations in the convection pattern cannot account for the very large spectral widths often observed by SuperDARN radars (André et al., 2000b). The large spectral widths are thought to be caused by electric field variations carried by ULF waves in the Pc 1-2 frequency range (André et al., 1999, 2000a), or shortscale electric fields radiating from filamentary field-aligned 
currents (Huber and Sofko, 2000). This implies SWBs may form in proximity to the OCB and elsewhere because of spatial and temporal variations in the activity of the spectral width drivers. However, spatial and temporal variations in the properties of the ionosphere may also contribute to the formation of SWBs.

It is well known that polarization effects enhance (suppress) electric fields in regions of low (high) heightintegrated Pedersen conductivity (Pedersen conductance). Whilst not definitive, Fig. 7 and previously published results actually suggest that the nightside SWB is often a better proxy for the poleward limit of hot electron and ion precipitation, $\sim 1 \mathrm{keV}$ and $10 \mathrm{keV}$, respectively (diamonds). This suggests that variations in E-region conductivity may play an important role in the formation of the SWB. The shortscale electric field fluctuations which cause the large spectral widths observed in the polar cap ionosphere must be shortedout or suppressed by the very large Pedersen conductance, $\Sigma_{p} \sim 10$ mhos, occurring in the nightside auroral oval. There is a theoretical basis, supported by measurements, for this hypothesis.

Weimer et al. (1985) analysed auroral field-perpendicular electric field measurements made by the Dynamics Explorer 1 (DE 1) spacecraft at high altitude, coincident with similar measurements made by the DE 2 spacecraft at low altitude. First, a magnetic dipole model was used to map the electric field strengths measured by the two spacecraft to the same height. Next, the electric field fluctuations were Fourier analysed during intervals when the measurements were made on nearly the same magnetic field lines. Similar large-scale $(>100 \mathrm{~km}$ ) electric field fluctuations were transmitted from high altitude to low latitude in and outside the auroral oval. However, within the auroral oval, the small-scale $(<100 \mathrm{~km})$ electric field fluctuations were suppressed at low altitude. This was mathematically consistent with the requirement of field-parallel potential drops and currents above auroral arcs of width $<100 \mathrm{~km}$.

Based on theory given by Lyons $(1980,1981)$ and Chiu et al. (1981), Weimer et al. derived an important equation describing the suppression of the low-altitude, ionospheric electric field $E_{x}^{i}$ with respect to the high-altitude, equatorial electric field $E_{x}^{h}$. Re-organising their Eq. (24), we obtain

$E_{x}^{i}=a /\left(a+\Sigma_{p} k^{2}\right) E_{x}^{h}$,

where $a$ is the finite parallel conductance, and $k$ is the wave number in the field-perpendicular direction. For large wavelengths, $k^{2} \rightarrow 0$, and $E_{x}^{i}=E_{x}^{h}$. For short wavelengths, $E_{x}^{i} / E_{x}^{h}$ decreases as $1 / k^{2}$. For $\Sigma_{p}=0$, all small-scale fluctuations are transmitted to the ionosphere, but as $\Sigma_{p}$ increases, only the large-scale fluctuations are transmitted. Because the smallscale fluctuations drive the field-perpendicular plasma motions causing the radar spectral widths, a SWB should form where there is a significant change in Pedersen conductance.

In fact, we can use the theory given in Weimer et al. to model the changes in nightside spectral widths shown in Figs. 3 and 6. Figure 5 showed that the mode (most probable) values of the three spectral width distributions were $\sim 15,55$, and $165 \mathrm{~m} \mathrm{~s}^{-1}$. We will show that the spectral width distributions with smaller mode values observed in the auroral oval can be explained solely by the Pedersen conductance suppressing the electric field fluctuations, as opposed to a reduction in the activity of the electric field fluctuation driver. However, we actually expect both factors to play a role.

First, we note that because $v=E / B$, Eq. (1) can also be used to map the magnitudes of the velocity fluctuations, $\Delta v$, corresponding to the electric field fluctuations. Next, we assume that the radar measurement process is linear, so that the observed spectral widths are given, to first order, by the magnitude of the velocity fluctuations throughout the observation cells (see Ponomarenko and Waters, 2003), i.e. the spectral widths are approximately determined by $\sim \Delta v$ at the spatial scales most likely to affect the observations. However, this is only an approximation because velocity fluctuations exist in both space and time. Nevertheless, the velocity fluctuations which do occur must still be given by $\sim \Delta v$.

The size of the observation cells at the ranges where most F-region ionospheric scatter is observed is of the order of $45 \mathrm{~km}$ by $100 \mathrm{~km}$ (i.e. the pulse width by the beam width). Although we will consider the effects of velocity fluctuations at all plausible scales affecting the observation cells, initially we only consider the effects of wave numbers $k$ corresponding to fluctuation scale sizes of 15,45 , and $90 \mathrm{~km}$. These and nearby fluctuation scale sizes will strongly affect the radar spectral widths.

We will assume that the spectral width distribution with a mode value of $\sim 165 \mathrm{~m} \mathrm{~s}^{-1}$ occurs in the polar cap ionosphere where $\Sigma_{p}=1$ mho. This initial choice is plausible given that $\Sigma_{p}$ is often $\sim 0.5$ to 2 mho in the dark polar cap. Next, the free parameter $a$ can be varied widely, but $a=2 \times 10^{-8} \mathrm{mho} \mathrm{m}^{-2}$ is consistent with the observations given in Weimer et al. (more on these choices later). Applying Eq. (1), we calculate the magnitude of the velocity fluctuations in the magnetosphere corresponding to the velocity fluctuations in the ionosphere for different spatial wave numbers $k$. The velocity fluctuations in the magnetosphere (mapped to the common ionospheric altitude) are 205, 326, $1613 \mathrm{~m} \mathrm{~s}^{-1}$ for fluctuation scale sizes of 15,45 , and $90 \mathrm{~km}$, respectively. For example, this means that velocity fluctuations of $326 \mathrm{~m} \mathrm{~s}^{-1}$ in the magnetosphere map to velocity fluctuations of $165 \mathrm{~m} \mathrm{~s}^{-1}$ in the polar cap ionosphere, at scale size $45 \mathrm{~km}$.

Having calculated the magnitude of the velocity fluctuations in the magnetosphere for various scale sizes, we now calculate what these values map to in the auroral ionosphere where the Pedersen conductance may be enhanced by energetic particle precipitation. We sort these results according to fluctuation scale size. Figure 10a shows the results for scale sizes of $15 \mathrm{~km}$ (bottom curve), $45 \mathrm{~km}$ (middle curve), and $90 \mathrm{~km}$ (top curve). Note that all three curves cross at the point where $\Sigma_{p}=1 \mathrm{mho}$ and $\Delta v=165 \mathrm{~m} \mathrm{~s}^{-1}$. If the spectral widths were entirely due to velocity fluctuations of scale size $15 \mathrm{~km}$, then the population of spectral widths with mode value $55 \mathrm{~m} \mathrm{~s}^{-1}$ can be explained by a Pedersen conductance 
of $3 \mathrm{mho}$, whereas the population with mode value $15 \mathrm{~m} \mathrm{~s}^{-1}$ can be explained by a Pedersen conductance of 12 mho. If we consider a fluctuation scale size of $45 \mathrm{~km}$, then these conductances increase to 5 and $20 \mathrm{mho}$, respectively. However, the conductances become implausibly large for scale sizes of $90 \mathrm{~km}$.

Figure 10b show the same calculations as in Fig. 10a, except the contours show the ionospheric spectral widths for all fluctuation scale sizes. Again, the auroral spectral width distributions with mode values of 55 and $15 \mathrm{~m} \mathrm{~s}^{-1}$ are best explained by fluctuation scale sizes of $45 \mathrm{~km}$ and less, and plausible Pedersen conductances of 5 to 20 mho. At larger scale sizes, unusually large values of Pedersen conductance must be invoked. Hence, our calculations are consistent with the notion that large SuperDARN spectral widths are caused by $\sim 10-\mathrm{km}$ scale size vortices generated by filamentary parallel currents (Huber and Sofko, 2000).

All of the curves in Fig. 10 change with our choice of $a$ or $\Sigma_{p}$ in the polar cap ionosphere. For example, increasing $\Sigma_{p}$ in the polar cap to 2 mho means that more conductance is required to explain the auroral spectral widths, and thus only $\sim 10-\mathrm{km}$ scale vortices can explain the observed spectral widths. Similarly, increasing the free parameter $a$ to $2 \times 10^{-7} \mathrm{mho} \mathrm{m}^{-2}$ means that more conductance is required to explain the auroral spectral widths, and again, only $\sim 10$-km scale vortices offer a viable explanation. However, decreasing $a$ to $2 \times 10^{-9}$ mho m$^{-2}$ means that even $100-\mathrm{km}$ scale size vortices can explain the observed spectral widths for plausible values of auroral conductance. Of course, the finite parallel conductance might be larger in the polar cap, and smaller in the auroral oval, but making this change does not change our conclusions.

Our first-order model shows the observed changes in the nightside spectral widths are consistent with the suppression of the electric field fluctuations by Pedersen conductance enhanced by particle-precipitation. However, our modeling does not exclude the possibility of ULF waves in the Pc 1-2 frequency range contributing to the generation of moderate spectral widths, as modeled by André et al. A future goal will be to simulate the complete spectral width distributions (e.g. Fig. 5) using a spectral width simulator similar to that of André et al., but incorporating the effects of ULF waves and spatio-temporal velocity fluctuations consistent with the Weimer et al. theory. Modeling is also required to establish whether the reflection coefficient of ULF waves becomes large for a highly conducting E-region. Depending on the wave mode, perhaps the electric field fluctuations carried by the incident and reflected waves are suppressed by enhanced ionospheric conductivity.

The preceding explanation of the SWB is consistent with the results of earlier studies. Dudeney et al. (1998), Fig. 3, suggests that as the energy and flux of precipitating particles (i.e. Pedersen conductance) increases, the amplitude of high frequency electric field fluctuations decreases, as well as the radar spectral widths. This is direct observational support for our hypothesis that the radar spectral widths are suppressed in regions of enhanced Pedersen conductance.

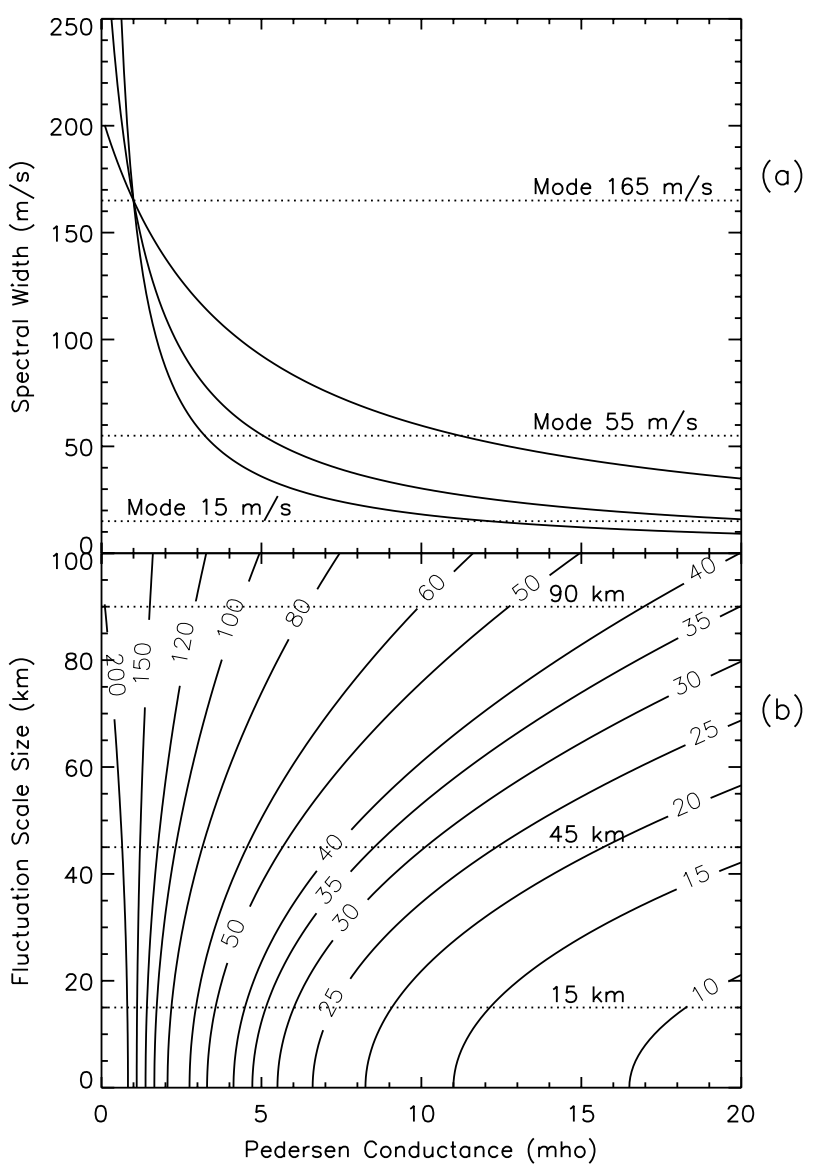

Fig. 10. (a) The three curves show the variation of the spectral width with Pedersen conductance for velocity fluctuations on spatial scales of $15 \mathrm{~km}$ (bottom curve), $45 \mathrm{~km}$ (middle curve), and $90 \mathrm{~km}$ (top curve). The calculations assume a most probable spectral width of $165 \mathrm{~m} \mathrm{~s}^{-1}$ in the polar cap ionosphere where $a=2 \times 10^{-8} \mathrm{mho} \mathrm{m}^{-2}$ and $\Sigma_{p}=1 \mathrm{mho}$, (b) The same calculations as in (a), except the contours show the spectral width versus Pedersen conductance for all auroral fluctuation scale sizes between zero and $100 \mathrm{~km}$.

Lester et al. (2001) and Parkinson et al. (2002b, 2003b ${ }^{1}$ ) reported DMSP poleward edges in agreement with the nightside radar SWB. In these studies, the hot particle precipitation tended to extend close to the poleward edge of the auroral oval. Parkinson et al. $(2003 \mathrm{~b})^{1}$ found that the OCB was less likely to agree with the SWB in the morning sector when colder precipitation extended poleward of the hot particle zone, i.e. again, the SWB was probably more closely aligned with the poleward edge of hot particle precipitation.

Parkinson et al. (2002b) showed that the large-scale velocities (electric fields) tend to rapidly decay across the nightside SWB, becoming slower and more laminar in the auroral oval. Again, this suggests that the small-scale turbulence observed by spacecraft within the plasma sheet does not completely map to the highly conducting auroral ionosphere. These observations are also consistent with the important role of Pedersen conductivity in the formation of the SWB. 


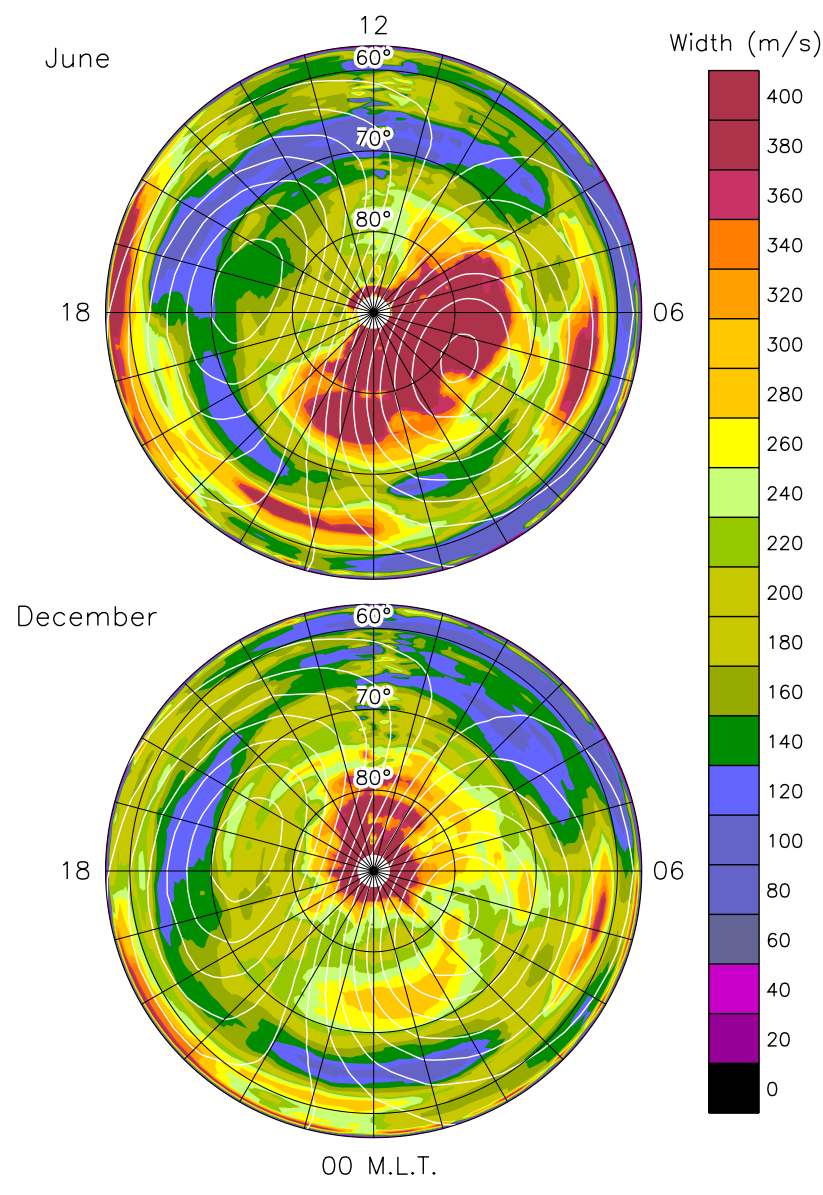

Fig. 11. Average Doppler spectral widths recorded on beam 4 and for all $K_{p}$ values during 30-day intervals centred on (a) June (winter) solstice and (b) December (summer) solstice for the years 2000 to 2003. The results have been smoothed with a median filter of width 5 to emphasise persistent large-scale variations. Similar to Fig. 1, equipotentials given by the DICM have been superimposed (white).

It is difficult to make firm conclusions using the complicated data sets presented by Woodfield et al. (2002a, b). She used EISCAT radar observations of the F-region to show that large spectral widths occur in regions of elevated plasma temperature. This implies particle precipitation on closed field lines, but some of the elevated temperatures may have been due to ion-neutral collisional heating or other polar cap processes. The spectral widths tended to be reduced in regions of larger F-region plasma density (conductivity), but no Eregion conductivity measurements were available. Her results do not contradict our hypothesis.

Recall that Pinnock and Rodger (2001) and Chisham et al. $(2001,2002)$ suggest that often the SWB does not indicate the location of the dayside OCB because of the ion travel time between the cusp reconnection site and its ionospheric projection, i.e. a role for particle precipitation, and thus ionospheric conductivity, is implicit. No doubt similar effects are present in the nightside SWB. Ultimately, the results of Woodfield et al. (2002a, b) may also be partly explained by particle and wave travel times between the ionosphere and magnetosphere.

If the SWB represents a transition from an ionospheric region of low conductance, such as the polar cap, to another region with large conductance, such as the auroral oval, then we might expect a SWB to form across the solar terminator as well. In general, the spectral widths will be suppressed by larger conductance in regions of direct solar illumination. Figure 11 shows average spectral widths recorded on TIGER beam 4 during 30-day intervals centred on (a) winter and (b) summer solstice during the years 2000 to 2003 . Clearly, large spectral widths are confined to the pre-noon cusp near summer solstice, whereas they extend further into the nightside ionosphere near winter solstice. Very large spectral widths probably still occur in the dayside summer ionosphere because the electric field fluctuations are so intense in the cusp. Although a strong seasonal variation due to changing geomagnetic activity exists, Fig. 11 does suggest that the spectral widths are suppressed by insolation.

\section{Closing remarks}

An understanding of the radar SWB outlined here is based upon the present results, as well as those of earlier, closely related studies. The HF radar SWB is a highly structured entity, constantly fluctuating in space, in time, and in all MLT sectors. Many of these fluctuations are strongly reminiscent of the way the OCB is expected to behave in the expanding/contracting model of the polar cap ionosphere. For example, the behaviour of the dayside SWB has been studied in considerable detail, and it is generally thought to correspond to the OCB under $B_{\mathrm{Z}}$ southward conditions (Baker et al., 1995; Milan et al., 1998; Moen et al., 2001). The dayside SWB clearly expands equatorward when $B_{\mathrm{Z}}$ is southward and contracts poleward when $B_{\mathrm{Z}}$ is northward (Pinnock et al., 1993).

The behaviour of the radar SWB can also be organised according to substorm phase. The present results and those of Parkinson et al. $(2003 b)^{1}$ suggest that the dayside SWB expands equatorward at the start of the growth phase of a substorm (i.e. when $B_{\mathrm{Z}}$ turns southward), continues expanding equatorward during the expansion phase, and then contracts poleward during the recovery phase. These dayside substorm signatures may be difficult to discern amidst the effects of ongoing changes in the dayside reconnection rate. Clearly, also, the transients described by Pinnock and Rodger (2001) and Chisham et al. (2001, 2002) must be taken into account.

Importantly, the nightside SWB also expands equatorward during the expansion phase, but by a lesser amount, and somewhat delayed with respect to the dayside expansion. The nightside SWB tends to undergo sudden, rapid poleward contractions during the recovery phase. These contractions may either represent the time at which the effects of nightside reconnection supercede the effects of dayside reconnection, or the arrival of the westward traveling surge. Future 
comparisons with space-based auroral images will help resolve this matter.

Combined, the work of Lester et al. (2001), Parkinson et al. (2002b, 2003b $\mathrm{b}^{1}$ ), and Chisham et al. (2004) prove that the radar SWB is often (but not always) a good proxy for the OCB between dusk and several hours past midnight. However, in this study we found several instances when this was not true. Woodfield et al. (2002a, b) had previously reported HF echoes with large spectral widths on closed field lines, post midnight. Figure 8 of this paper reveals an equatorward tilt of the SWB in the morning sector, whereas the OCB is not expected to behave in this way. The radar SWB is not a reliable proxy for the OCB in the post-midnight to dawn sector, but it tends to become a better proxy again near dawn.

Overall, the comparisons between the location of the radar SWB and DMSP spectra for all of the preceding studies suggest that the nightside SWB is formed closer to the poleward limit of hot particle precipitation than the OCB. The regions of hot particle precipitation probably correspond to regions of large Pedersen conductance which may attenuate the mechanism driving the large spectral widths. The results of Parkinson et al. (2003b) ${ }^{1}$ suggest that the poleward edge of the auroral oval can agree with the location of the nightside SWB during all phases of a substorm.

Recall that there is still no consensus about the mechanism driving the large spectral widths observed by SuperDARN radars, but that the calculations in the preceding section imply a major role for $10-\mathrm{km}$ scale electric field fluctuations emanating from filamentary field-aligned currents. However, ULF waves in the Pc 1-2 frequency range may also contribute, with their effects adding in quadrature to determine spatial and temporal variability in the radar spectral widths. Ultimately, the actual spectral widths observed will be determined by the product of variability in these spectral width drivers multiplied by the tendency for enhanced Pedersen conductivity to suppress the electric field fluctuations.

Our observations are reminiscent of the observations used to detect the OCB in incoherent scatter radar data, namely that latitudinal transitions in the observed electron density profiles indicate the presence of different particle precipitation regimes (Blanchard et al., 2001). The hypothesis that the HF radar SWB often forms near a step-like change in Pedersen conductance requires further testing. For example, we expect that each radar will observe a unique variation in the distribution functions of spectral width with MLT and latitude. This is because of variations in the offset of the geodetic and geomagnetic poles, and concomitant variations in conductivity due to insolation, precipitation, and plasma transport. Good agreement may also be obtained by calculating Pedersen conductance using satellite measurements of precipitating particle fluxes, and better still, direct measurements of plasma density using incoherent scatter radar. The present choice of electron and ion energies $\sim 1 \mathrm{keV}$ and $10 \mathrm{keV}$ is somewhat arbitrary. Modeling may reveal that smaller (larger) particle fluxes and conductivity enhancements are required to suppress the spectral widths in the nightside ionosphere (cusp) where the electric field fluctuations are less (more) intense.

The location of the radar SWB will not always agree with the location of the OCB for other reasons. The dayside SWB may fluctuate rapidly because of fluctuations in the solar wind/IMF, namely the direct impact of flux transfer events on the OCB. The ion travel time may lead to the separation of the true OCB from the low altitude particle precipitation boundary (i.e. Pinnock and Rodger, 2001; Chisham et al., 2001, 2002). The time delay for ions and waves to travel between the magnetotail and ionosphere may eventually explain discrepancies between the location of the nightside SWB and OCB. Just as the dayside SWB tends to be located poleward of the dayside OCB because of antisunward convection, it is logical to expect that the nightside SWB will be located equatorward of the nightside OCB (see the analysis given by Lockwood, 1997).

Conceivably, multiple SWBs may be observed on the same beam because of s-shaped features in the same, continuous SWB. Figure 3b illustrated another condition. It showed a SWB identified near $-67^{\circ} \Lambda$ during 11:40 to 13:05 UT, but at the same time there was also a SWB near $-83^{\circ} \Lambda$. As previously discussed, the latter was probably just a "scatter boundary", or simply the range at which 1.5-hop radio waves re-entered the F-region ionosphere. Figure 6 actually illustrated the occurrence of genuine multiple SWBs, possibly caused by spatial variations in three or more prevalent levels of ionospheric conductance, and thus spectral width distributions. When averaging over longer time intervals, these discrete distributions blend into a continuum of distributions, forming a single, dominant distribution below the SWB, and a single, dominant distribution above the SWB. Hence, populations A and B defined in Fig. 9 of Parkinson et al. (2003a) were averages over numerous localised distributions.

The dayside SWB has not always been identified as a transition between ionospheric scatter with low $\left(<50 \mathrm{~m} \mathrm{~s}^{-1}\right)$ and high spectral width $\left(>200 \mathrm{~m} \mathrm{~s}^{-1}\right)$. Rather, the cusp scatter with high spectral width has been thought of as a hard target (Milan et al., 1998), and its equatorward edge taken as the SWB. No doubt using the scatter boundary is valid when the dayside scatter is observed entirely within the preferred range window supported by the propagation conditions. However, the SWB is most likely to correspond to a Pedersen conductance boundary (or OCB) when it is identified as a sharp transition between ionospheric scatter with low and high spectral widths in the preferred range window for detection using 0.5 hop, and sometimes 1.5-hop propagation.

Another aspect of HF propagation must be considered. There is a possibility that en route to the F-region irregularities producing scatter with large spectral widths, the radio waves encounter E-region irregularities producing scatter with low spectral widths. Hence, the SWB may actually represent a transition in ionospheric properties which change with height, as opposed to magnetic latitude. So far, our interferometer measurements of elevation angle have provided no evidence to support this view. Moreover, we recently conducted discretionary campaigns in which the SWB location 
was measured concurrently on many well-separated transmitter frequencies. The SWB location was mostly independent of frequency, suggesting that it does not represent a transition between propagation conditions favouring detection of E- and F-region scatter.

Paradoxically, very low spectral widths are sometimes observed in the central polar cap ionosphere (e.g. Fig. 1, 17:03:40 UT scan). We expect that very low spectral widths will be observed when the ionospheric conductivity is enhanced by theta aurora, polar storms, and polar cap absorption events. Alternatively, these very low spectral widths may be related to a reduction in the electric field fluctuations occurring on open field lines in the magnetosphere or beyond. If the multiplicative effect of the drivers could be separated, SuperDARN spectral widths might map out the variation of Pedersen conductance variations in the high-latitude ionosphere.

SuperDARN radars have the potential to identify the SWB on all 16 beams every minute or two, and thereby monitor evolution of the SWB shape in longitude and time. If the same SWB shape tends to persist during consecutive full scans, then it seems likely that this shape is essentially stationary in longitude. Unfortunately, by the time the radar FOV has rotated to a completely new MLT sector, the observed changes in shape may have been caused by spatial or temporal variations. When conditions favour the simultaneous detection of ionospheric scatter in many adjacent radar FOVs, SuperDARN has the potential to discriminate between spatial and temporal variations in SWB shape around many hours of MLT. The network of SuperDARN radars in the Northern Hemisphere presently encircles $\sim 2 / 3$ of the highlatitude ionosphere, but the coverage in the Southern Hemisphere is not as extensive.

The TIGER radar does a very good job of identifying the SWB shape in the evening and midnight sectors, but it will struggle to measure a SWB shape with a poleward tilt toward the east in the morning sector. This is because the easternmost beams only attain a relatively low magnetic latitude. However, a second TIGER radar with overlapping FOV is presently being constructed in New Zealand. Its FOV will be complementary to that of the existing TIGER radar, and thus will favour identification of the SWB shape in the morning sector, but not the evening sector. Construction of a third radar at even lower latitude will also permit the study of the nightside SWB behaviour during major geomagnetic storms.

Acknowledgements. This work was supported by the Australian Research Council, the Australian Antarctic Science Advisory Committee, and the Australian Academy of Sciences. D. J. McComas of the Los Alamos National Laboratory and N. F. Ness of the Bartol Research Institute are thanked for making ACE solar wind and magnetic field data available, respectively. Geoscience Australia is thanked for making MQI fluxgate magnetometer data available. The DMSP particle detectors were designed by D. Hardy of AFRL, and data were obtained from JHU/APL. We thank D. Hardy, F. Rich, and P. Newell for its use. We thank S. Wing of JHU/APL for helping us to interpret the DMSP energy spectra.
Topical Editor M. Lester thanks J. Wild and another referee for their help in evaluating this paper.

\section{References}

Anderson, P. C., McCrea, I. W., Strickland, D. J., Blake, J. B., and Looper, M. D.: Coordinated EISCAT/DMSP measurements of electron density and energetic electron precipitation, J. Geophys. Res., 102, 7421-7430, 1997.

André, R., Pinnock, M., and Rodger, A. S.: On the SuperDARN autocorrelation function observed in the ionospheric cusp, Geophys. Res. Lett., 26, 3353-3356, 1999.

André, R., Pinnock, M., and Rodger, A. S.: Identification of the low-altitude cusp by Super Dual Auroral Radar Network radars: A physical explanation for the empirically derived signature, J. Geophys. Res., 105, 27 081-27 093, 2000a.

André, R., Pinnock, M., Villain, J.-P., and Hanuise, C.: On the factors conditioning the Doppler spectral width determined from SuperDARN HF radars, Int. J. Geomag. Aeronomy, 2, 77-86, 2000 b.

Baker, D. N., Pulkkinen, T. I., Büchner, J., and Klimas, A. J.: Substorms: A global instability of the magnetosphere-ionosphere system, J. Geophys. Res., 104, 14 601-14 611, 1999.

Baker, K. B. and Wing, S.: A new magnetic coordinate system for conjugate studies of high latitudes, J. Geophys. Res., 94, 91399143, 1989.

Baker, K. B., Dudeney, J. R., Greenwald, R. A., et al.: HF radar signatures of the cusp and low-latitude boundary layer, J. Geophys. Res., 100, 7671-7695, 1995.

Blanchard, G. T., Lyons, L. R., and Samson, J. C.: Accuracy of using $6300 \AA$ auroral emission to identify the magnetic separatrix on the nightside of Earth, J. Geophys. Res., 102, 9697-9703, 1997.

Blanchard, G. T., Ellington, C. L., and Lyons, L. R.: Incoherent scatter radar identification of the dayside magnetic separatrix and measurements of magnetic reconnection, J. Geophys. Res., 106, 8185-8195, 2001.

Chisham, G. and Freeman, M. P.: A technique for accurately determining the cusp-region polar cap boundary using SuperDARN HF radar measurements, Ann. Geophys., 21, 983-996, 2003.

Chisham, G. and Freeman, M. P.: An investigation of latitudinal transitions in the SuperDARN Doppler spectral width parameter at different magnetic local times, Ann. Geophys., 22, 1187-1202, 2004.

Chisham, G., Pinnock, M., and Rodger, A. S.: The response of the HF radar spectral width boundary to a switch in the IMF By direction: Ionospheric consequences of transient dayside reconnection?, J. Geophys. Res., 106, 191-202, 2001.

Chisham, G., Pinnock, M., Coleman, I. J., Hairston, M. R., and Walker, A. D. M.: An unusual geometry of the ionospheric signature of the cusp: implications for magnetopause merging sites, Ann. Geophys., 20, 29-40, 2002.

Chisham, G., Freeman, M. P., and Sotirelis, T.: A statistical comparison of SuperDARN spectral width boundaries and DMSP particle precipitation boundaries in the nightside ionosphere, Geophys. Res. Lett., 31, L02804, doi:10.1029/2003GL019074, 2004.

Chiu, Y. T., Newman, A. L., and Cornwall, J. M.: On the structure and mapping of auroral electrostatic potentials, J. Geophys. Res., 86, 10 029-10 037, 1981.

Cowley, S. W. H. and Lockwood, M.: Excitation and decay of solar wind-driven flows in the magnetosphere-ionosphere system, 
Ann. Geophys., 10, 103-115, 1992.

Dudeney, J. R., Rodger, A. S., Freeman, M. P., Pickett, J., Scudder, J., Sofko, G., and Lester, M.: The nightside ionospheric response to IMF By changes, Geophys. Res. Lett., 25, 2601-2604, 1998.

Dyson, P. L. and Devlin, J. C.: The Tasman International Geospace Environment Radar, The Physicist (The Australian Institute of Physics), 37, 48-53, March/April, 2000.

Evans, L. C. and Stone, E. C.: Electron polar cap and the boundary of open geomagnetic field lines, J. Geophys. Res., 77, 55805584, 1972.

Gauld, J. K., Yeoman, T. K., Davies, J. A., Milan, S. E., and Honary, F.: SuperDARN radar HF propagation and absorption response to the substorm expansion phase, Ann. Geophys., 20, 1631-1645, 2002.

Greenwald, R. A., Baker, K. B., Hutchins, R. A., and Hanuise, C.: An HF phased-array radar for studying small-scale structure in the high-latitude ionosphere, Radio Sci., 20, 63-79, 1985.

Greenwald, R. A., Baker, K. B., Dudeney, J. R., et al.: DARN/SuperDARN: A global view of the dynamics of highlatitude convection, Space Sci. Rev., 71, 761-796, 1995.

Huber M. and Sofko G. J.: Small-scale vortices in the high-latitude F region, J. Geophys. Res., 105(A9), 20 885-20 897, 2000.

Lester, M., Milan, S. E., Besser, S. E., and Smith, R.: A case study of HF radar spectra and $630.0 \mathrm{~nm}$ auroral emission in the premidnight sector, Ann. Geophys., 19, 327-339, 2001.

Lewis, R. V., Freeman, M. P., Rodger, A. S., Reeves, G. D., and Milling, D. K.: The electric field response to the growth phase and expansion phase onset of a small isolated substorm, Ann. Geophys., 15, 289-299, 1997.

Lewis, R. V., Freeman, M. P., and Reeves, G. D.: The relationship of HF radar backscatter to the accumulation of open magnetic flux prior to substorm onset, J. Geophys. Res., 103, 26613-26619, 1998.

Lockwood, M.: Relationship of dayside auroral precipitations to the open-closed separatrix and the pattern of convective flow, J. Geophys. Res., 102, 17475-17487, 1997.

Lui, A. T. Y.: Current controversies in magnetospheric physics, Rev. Geophys., 39, 535-563, 2001.

Lyons, L. R.: Generation of large-scale regions of auroral currents, electric potentials, and precipitation by divergence at the convection electric fields, J. Geophys. Res., 85, 17-24, 1980.

Lyons, L. R.: Discrete aurora as the direct result of an inferred highaltitude generating potential distribution, J. Geophys. Res., 86, $1-8,1981$.

Milan, S. E., Yeoman, T. K., and Lester, M.: The dayside auroral zone as a hard target for coherent HF radars, Geophys. Res. Lett., 25, 3717-3720, 1998.

Milan, S. E., Davies, J. A., and Lester, M.: Coeherent HF radar backscatter characteristics associated with auroral forms identified by incoherent radar techniques: a comparison of CUTLASS and EISCAT observations, J. Geophys. Res., 104, 22 591-22 604, 1999.

Milan, S., Lester, M., Cowley, S. W. H., and Brittnacher, M.: Convection and auroral response to a southward turning of the IMF: Polar UVI, CUTLASS, and IMAGE signatures of transient magnetic flux transfer at the magnetopause, J. Geophys. Res., 105, 15 741-15 755, 2000.

Moen, J., Carlson, H. C., Milan, S. E., Shumilov, N., Lybekk, B., Sandholt, P. E., and Lester, M.: On the collocation between dayside auroral activity and coherent HF radar backscatter, Ann. Geophys., 18, 1531-1549, 2001.

Newell, P. T., Feldstein, Y. I., Galperin, Y. I., and Meng, C.-I.:
Morphology of nightside precipitation, J. Geophys. Res., 101, 10737-10 748, 1996.

Norman, R. J., Parkinson, M. L., and Dyson, P. L.: Comparing HF radar backscatter from the Southern Ocean with ray-tracing results using the IRI model, Proceedings of the Workshop on the Applications of Radio Science, Hobart, Tasmania, 18-20 February, 2004.

Papitashvili, V. O. and Rich, F. J.: High-latitude ionospheric convection models derived from Defense Meteorological Satellite Program ion drift observations and parameterized by the interplanetary magnetic field strength and direction, J. Geophys. Res., 107(A8), doi:10.1029/2001JA000264, 2002.

Parkinson, M. L., Monselesan, D. P., Smith, P. R., Dyson, P. L., and Morris, R. J.: Digital ionosonde measurements of the height variation of drift velocity in the southern polar cap ionosphere: initial results, J. Geophys. Res., 102, 24 075-24 090, 1997.

Parkinson, M. L., Breed, A. M., Dyson, P. L., and Morris, R. J.: Signatures of the ionospheric cusp in digital ionosonde measurements of plasma drift above Casey, Antarctica, J. Geophys. Res., 104, 22 487-22 498, 1999.

Parkinson, M. L., Devlin, J. C., Dyson, P. L., Pinnock, M., Ye, H., Morris, R. J., and Waters, C. L.: Diurnal, seasonal, and geomagnetic activity variations in the occurrence of decametrescale irregularities in the auroral and subauroral ionosphere, Proceedings of the Workshop on the Applications of Radio Science, Leura, New South Wales, 20-22 February, 2002a.

Parkinson, M. L., Dyson, P. L., Pinnock, M., Devlin, J. C., Hairston, M. R., Yizengaw, E., and Wilkinson, P. J.: Signatures of the midnight open-closed magnetic field-line boundary during balanced dayside and nightside reconnection, Ann. Geophys., 20, 1617 1630, 2002b.

Parkinson, M. L., Pinnock, M., Dyson, P. L., Devlin, J. C., Waters, C. L., Smith, P. R., and Breed, A. M.: Multiple time delays between IMF-driven convection changes at cross polar locations in the high-latitude ionosphere, Internal Report, Department of Physics, La Trobe Univ., 2002c.

Parkinson, M. L., Devlin, J. C., Ye, H., Waters, C. L., Dyson, P. L., Breed, A. M., and Morris, R. J.: On the occurrence and motion of decametre-scale irregularities in the sub-auroral, auroral, and polar cap ionosphere, Ann. Geophys., 21, 1847-1868, 2003 a.

Pinnock, M., Rodger, A. S., Dudeney, J. R., Baker, K. B., Newell, P. T., Greenwald, R. A., and Greenspan, M. E.: Observations of an enhanced convection channel in the cusp ionosphere, J. Geophys. Res., 98, 3767-3776, 1993.

Pinnock, M. and Rodger, A. S.: On determining the noon polar cap boundary from SuperDARN HF radar backscatter characteristics, Ann. Geophys., 18, 1523-1530, 2001.

Ponomarenko, P. V. and Waters, C. L.: The role of Pc 1-2 waves in spectral broadening of SuperDARN echoes from high latitudes, Geophys. Res. Lett., 30, doi:10.1029/2002GL016333, 2003.

Siscoe, G. L. and Huang, T. S.: Polar cap inflation and deflation, J. Geophys. Res., 90, 543-547, 1985.

Stenuit, H., Fujimoto, M., Fuselier, S. A., Sauvaud, J.-A., Wing, S., Fedorov, A., Budnik, E., Savin, S. P., Trattner, K. J., Angelopoulos, V., Bonnel, J., Phan, T. D., Mukai, T., and Pedersen, A.: Multi-spacecraft study of the dynamics of the suk-flank magnetosphere under northward IMF: January 10-11, 1997, J. Geophys. Res., 107(A10), doi:10.1029/2002JA009246, 2002.

Thorolfsson, A., Cerisier, J.-C., and Pinnock, M.: Flow transients in the postnoon ionosphere: The role of solar wind dynamic pressure, J. Geophys. Res., 106, 1887-1901, 2001.

Vampola, A. L.: Access of solar electrons to closed field lines, J. 
Geophys. Res., 76, 36-43, 1971.

Vickrey, J. F. and Kelley, M. C.: The effects of a conducting E layer on classical $\mathrm{F}$ region cross-field plasma diffusion, J. Geophys. Res., 87, 4461-4468, 1982.

Villain, J. P., Caudal, G., and Hanuise, C.: A SAFARI-EISCAT comparison between the velocity of $\mathrm{F}$ region small-scale irregularities and ion drift, J. Geophys. Res., 90, 8433-8444, 1985.

Villain, J. P., André, R., Pinnock, M., Greenwald, R. A., and Hanuise, C.: A statistical study of the Doppler spectral width of high latitude ionospheric F region recorded with SuperDARN coherent HF radars, Ann. Geophys., 20, 1769-1781, 2002.

Weimer, D. R., Goertz, C. K., Gurnett, D. A., Maynard, N. C., and Burch, J. L.: Auroral zone electric fields from DE 1 and 2 at magnetic conjunctions, J. Geophys. Res., 90, 7479-7494, 1985.
Wing, S. and Newell, P. T.: 2D plasma sheet density profile for northward and southward IMF, Geophys. Res. Lett., 29(9), doi:10.1029/2001GL013950, 2002.

Woodfield, E. E., Davies, J. A., Eglitis, P., and Lester, M.: A case study of HF radar spectral width in the post-midnight magnetic local time sector and its relationship to the polar cap boundary, Ann. Geophys., 20, 501-509, 2002a.

Woodfield, E. E., Davies, J. A., Lester, M., Yeoman, T. K., Eglitis, P., and Lockwood, M.: Nightside studies of coherent HF radar spectral width behaviour, Ann. Geophys., 20, 1399-1413, 2002 b.

Woodfield, E. E., Hosokawa, K., Milan, S. E., Sato, N., and Lester, M.: An inter-hemispheric, statistical study of nightside spectral width distributions from coherent HF scatter radars studies, Ann. Geophys., 20, 1921-1934, 2002c. 